Ann. rheum. Dis. (1957), 16, 35.

\title{
ENZYMATIC ELUCIDATION OF THE RELATIONSHIP BETWEEN COLLAGEN AND ELASTIN : AN ELECTRON-MICROSCOPIC STUDY
}

\author{
BY \\ M. K. KEECH* AND R. REED \\ Departments of Medicine and Leather Industries, University of Leeds
}

(RECEIVED FOR PUBLICATION OCTOBER 15, 1956)

Any information on the reaction of the fibrous connective tissue components to various reagents, particularly enzymes, is of interest in the fields of both health and disease. Until some understanding of the normal interrelationships of these structures is reached, no firm attempt to explain pathological findings can be made. Although it is dangerous to extrapolate test-tube results in explanation of changes found in vivo, most of the agents and conditions used in the present study are not too far removed from possible conditions in living mammals. Elastase and hyaluronidase are manufactured in man and recently collagenase activity has been demonstrated in canine pancreatic juice (Ziffren and Hosie, 1955). The mildly alkaline solutions employed could represent a $p \mathrm{H}$ value reached in pathological tissue, and most of the experiments were conducted at body temperature.

Although previous work (Keech, Reed, and Wood, 1956) demonstrated that "moth-eaten" fibres (MEF) were intermediate structures midway between collagen and elastin, the present study shows without doubt that a further range of agents (physical, chemical, enzymatic) can cause breakdown of these structures to "elastin". Concurrent experiments on elastin are described, and objections raised to the use of the standard elastin substrate for electron microscopic work.

\section{Materials and Methods}

Prepared Collagen.-One of the same substrates used in previous work (Keech, 1954, 1955; Keech

\footnotetext{
* Empire Rheumatism Council Research Fellow.
}

and others, 1956) was chosen for use throughout this study as it was known that the deposit, after incubation with collagenase for $24 \mathrm{hrs}$, consisted almost entirely of "moth-eaten" fibres.

Preparations of "Moth-Eaten" Fibres (MEF).Prepared collagen from the abdominal skin of a 2-year-old child was incubated with collagenase in

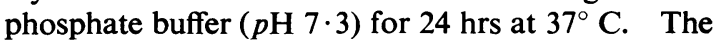
remaining material was centrifuged and the pellet treated in one of the following ways:

(a) Re-suspended in borate buffer $(p \mathrm{H} 8 \cdot 8)$ and incubated at $37^{\circ} \mathrm{C}$., samples being taken after 3,12 , and $24 \mathrm{hrs}$.

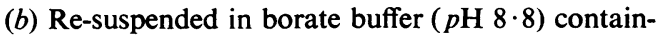
ing $0.2 \mathrm{mg}$. elastase, samples being taken as in $(a)$.

(c) Re-suspended in phosphate buffer $(p \mathrm{H} \mathrm{7 \cdot 3)}$ and a further $0.5 \mathrm{mg}$. of collagenase added. Samples were taken after 3,6 , and $12 \mathrm{hrs}$ incubation at $37^{\circ} \mathrm{C}$.

(d) Re-suspended in sterile distilled water in a dialysis bag and submitted to ultrasonic radiation for $30 \mathrm{~min}$. at $25^{\circ} \mathrm{C}$.

(e) Re-suspended in sterile distilled water containing half an ampoule of Benger's "Hyalase" and incubated at $37^{\circ} \mathrm{C}$. Samples were taken at $1 \frac{1}{2}$, 3,6 , and 24 hrs. 
Preparations of Elastin.-Collagen-free ox ligamentum nuchae in the form of a fine powder (passed through a 40-60 mesh) was kindly supplied by Dr. D. A. Hall. This was:

(a) Suspended in sterile distilled water and heated at $55^{\circ} \mathrm{C}$. for $1 \mathrm{hr}$, at $75^{\circ} \mathrm{C}$. for a further hour and finally at $110^{\circ} \mathrm{C}$. for $1 \mathrm{hr}$, samples being taken at the end of each hour.

(b) Suspended in phosphate buffer $(p \mathrm{H} 7 \cdot 3)$ and incubated at $37^{\circ} \mathrm{C}$., samples being taken after 24 , 35 , and 48 hours.

(c) Suspended in phosphate buffer $(p \mathrm{H} \mathrm{7 \cdot 3)} \mathrm{contain-}$ ing $0.5 \mathrm{mg}$. collagenase and incubated at $37^{\circ} \mathrm{C}$. for $24 \mathrm{hrs}$. This was sampled, a further $0.5 \mathrm{mg}$. collagenase was added, and specimens were taken at 35 and $48 \mathrm{hrs}$. The 48 -hr tube was again sampled after storage at $5^{\circ} \mathrm{C}$. for $3 \mathrm{wks}$.

Antibiotics. $-0.05 \mathrm{ml}$. of a penicillin and streptomycin mixture was added to each test tube in the above experiments.

Enzymes.-Cl. histolyticum collagenase was kindly supplied by Dr. J. D. MacLennan, the same batch being used throughout. The elastase was prepared by Hall and Gardiner (1955).

Samples for Electron Microscopic Examination.These were ground gently in a glass tissue grinder until a milky suspension was obtained; drops were placed on collodion-covered 200-mesh copper grids, drained with filter paper, allowed to dry, washed with sterile distilled water, shadowed with chromium, and examined in a Siemens electron microscope, type UM $60 \mathrm{C}$.

Counts of the different elastic structures were made by carefully scanning two grids from each sample. The specimen holder had been adjusted to visualize 25 squares of the grid, and each part of each square was examined in sequence. As each square was scanned at a magnification of 11,000 , and as about 25 fields were needed to cover each square, a minimum of $1,250(2 \times 625)$ fields were scrutinized from each specimen.

Terminology.-The presence of several types of elastin, throughout this paper is somewhat confusing. For clarity, three groups are distinguished:

(a) Naturally-occurring elastin, or "fully-formed elastin", as described previously (Keech and others, 1956), comprising three variants (skintype, filamenting, and large natural networks) which are found in fresh whole dermis and prepared dermis from all age groups, aorta, tendon, and ox ligamentum nuchae. This appears in the text without quotation marks.

(b) Morphologically identical structures seen after a variety of procedures are referred to as "elastin" or elastin-like structures.

(c) The ox ligamentum nuchae elastin powder was obtained by treating the ligament with boiling 1 per cent. acetic acid solution for $1 \mathrm{hr}$. Although the desirability of this method of preparation and the purity of the product are debated below in the Discussion, it is accorded its time-honoured status as true elastin and appears in the text without quotation marks.

\section{Results}

\section{Macroscopic Changes}

In preparing the "moth-eaten" fibres, $85-90$ per cent. of the original 2-year-old prepared collagen was digested. However, the subsequent treatments to the MEF deposit did not produce any identifiable macroscopic change in the relatively small quantities used. The ox ligamentum nuchae powder heated in water appeared unaltered, as did the buffer $(p \mathrm{H} \mathrm{7 \cdot 3)}$ heat control. The collagenase-treated supernatant became progressively opaque in comparison with the water-clear control, the difference being very marked at $48 \mathrm{hrs}$.

Under the light microscope at 35 and $48 \mathrm{hrs}$, this test deposit was much finer than the control, with large, long, irregular structures in place of the smooth-edged, highly refractile fibres present in both the starting material and the control.

\section{Electron Microscopic Findings}

\section{(A) Preparations of MEF (Table I, opposite)}

The starting material showed the usual picture of "moth-eaten" fibres mixed with amorphous debris, beaded fibrils, masses of "beads", and scanty filamentin!s elastin (Keech, 1955; Keech and others, 1956) (Fig. 1, overleaf). In addition, some of the MEF were starting to break up into short lengths terminating as "elastic networks" (MEFC) (Fig. 2, overleaf) or ribbons of "filamenting elastin". Although the majority of the many samples examined from the two different batches of MEF starting material were collagen-free, a very small quantity (twenty solitary fibrils and a few groups) was seen in the second batch, but lacked any evidence of "standard" collagenase change (Keech, 1955). The fine thread-like structures previously described (Keech and others, 1956) were absent. 
TABLE I

SUMMARY OF RESULTS OF EXPERIMENTS PERFORMED ON “MOTH-EATEN" FIBRES (MEF) AT LEAST 1,250 MICROSCOPIC FIELDS WERE EXAMINED AT EACH TIME-INTERVAL

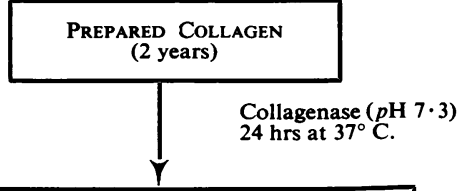

Two Batches of MEF Starting Material MEF, dense bits, amorphous material, beaded fibrils and "beads"

A few MEFC and filamenting elastin

No fine threads

Very scanty collagen in second batch only

Ultrasonics Moderate MEF breakdown $\rightarrow$ Filamenting elastin 30 min. at $25^{\circ} \mathrm{C}$. MEFC

No fine threads

\begin{tabular}{|c|c|c|c|c|c|c|}
\hline \multicolumn{5}{|c|}{ FIRST BATCH } & \multicolumn{2}{|r|}{ SECOND BATCH } \\
\hline Time & BUfFER CONTROL ( $p$ H $8 \cdot 8)$ & ELASTASE $(p \mathrm{H} 8 \cdot 8)$ & Time & Collagenase $(p \mathrm{H} 7 \cdot 3)$ & Time & Hyaluronidase \\
\hline $\begin{array}{c}3 \\
\text { hrs } \\
\text { at } \\
37^{\circ} \mathrm{C}\end{array}$ & $\begin{array}{l}\text { Same as starting material } \\
\text { only MEF more disin- } \\
\text { tegrated revealing "elas- } \\
\text { tic networks" } \\
\text { No collagen }\end{array}$ & $\begin{array}{l}\text { No MEF } \\
\text { Numerous MEFC } \\
\text { Much "filamenting" and } \\
\text { "elastic networks" } \\
\text { No collagen }\end{array}$ & $\begin{array}{c}3 \\
\text { hrs } \\
\text { at } \\
37^{\circ} \mathrm{C}\end{array}$ & $\begin{array}{l}\text { MEF in all stages of break- } \\
\text { down } \\
\text { "Filamenting elastin" } \\
\text { Numerous fine threads } \\
\text { No collagen }\end{array}$ & $\begin{array}{c}1 \frac{1}{2} \\
\text { hrs } \\
\text { at } \\
37^{\circ} \mathrm{C}\end{array}$ & $\begin{array}{l}\text { Commencing MEF-break- } \\
\text { down } \\
\text { MEFC } \\
\text { "Filamenting elastin" } \\
\text { No fine threads } \\
\text { Scanty collagen }\end{array}$ \\
\hline $\begin{array}{c}12 \\
\text { hrs } \\
\text { at } \\
37^{\circ} \mathrm{C}\end{array}$ & $\begin{array}{l}\text { Same as at } 3 \text { hrs only } \\
\text { MEF scantier, thinner, } \\
\text { and more disintegrated }\end{array}$ & $\begin{array}{l}\text { Scanty deposit of dense bits, } \\
\text { and a few tiny "elastic } \\
\text { networks" and plaque- } \\
\text { like remnants of MEF }\end{array}$ & $\begin{array}{c}6 \\
\text { hrs } \\
\text { at } \\
37^{\circ} \mathrm{C}\end{array}$ & $\begin{array}{l}\text { Increased breakdown of } \\
\text { MEF } \\
\text { Numerous beaded fibrils } \\
\text { and "beads", and fine } \\
\text { threads } \\
\text { No collagen }\end{array}$ & $\begin{array}{l}3 \\
\text { hrs } \\
\text { at } \\
37^{\circ} \mathrm{C}\end{array}$ & $\begin{array}{l}\text { No MEF } \\
\text { Numerous MEFC } \\
\text { "Filamenting elastin", } \\
\text { No fine threads } \\
\text { Scanty collagen }\end{array}$ \\
\hline $\begin{array}{c}24 \\
\text { hrs } \\
\text { at } \\
37^{\circ} \mathrm{C}\end{array}$ & $\begin{array}{l}\text { Increased breakdown to } \\
\text { "elastic networks" and } \\
\text { "core" of elastin }\end{array}$ & Same as at $12 \mathrm{hrs}$ & $\begin{array}{c}12 \\
\text { hrs } \\
\text { at } \\
37^{\circ} \mathrm{C}\end{array}$ & $\begin{array}{l}\text { Breakdown products of } \\
\text { MEF } \\
\text { Numerous beaded fibrils } \\
\text { and "beads", and fine } \\
\text { threads } \\
\text { No collagen }\end{array}$ & $\begin{array}{c}6 \\
\text { hrs } \\
\text { at } \\
37^{\circ} \mathrm{C}\end{array}$ & $\begin{array}{l}\text { Increased breakdown to } \\
\text { "elastic networks" and } \\
\text { "core" of elastin } \\
\text { Scanty collagen }\end{array}$ \\
\hline \multicolumn{3}{|c|}{$\begin{array}{l}\text { 6-hr elastase and control experiments reported previously } \\
\text { (Keech, Reed, and Wood, 1956) } \\
\text { Test deposit showed dramatic change to numerous large } \\
\text { elastic networks and MEFC }\end{array}$} & & & $\begin{array}{c}24 \\
\text { hrs } \\
\text { at } \\
37^{\circ} \mathrm{C}\end{array}$ & $\begin{array}{l}\text { Small undigested remnants } \\
\text { Scanty collagen } \\
\text { No fine threads }\end{array}$ \\
\hline
\end{tabular}

Effect of Borate Buffer alone ( $p \mathrm{H} 8 \cdot 8$ ) on MEF.After $3 \mathrm{hrs}$ ' incubation the picture closely resembled the starting material, except that more MEF were starting to break down to form more MEFC. Fig. 3 (overleaf) shows a recently disintegrated portion represented as a localized patch of "beads" several layers thick. This had presumably linked the "elastic network" in the corner of the picture to the main MEF. At 12 hrs the picture was similar to that at $3 \mathrm{hrs}$, only the MEF were scantier, thinner, and more disintegrated (Fig. 4, overleaf). There was an increase in elastin-like structures, both as filamenting and as networks. At 24 hrs only three unaltered MEF were seen, the deposit consisting of MEF in all stages of breakdown. As illustrated in Figs 5 to 8 (overleaf) this process appeared to take place as follows:

First, a reduction in the dense amorphous coating (elastomucin) of the MEF, rendering it thinner both in width and thickness.
Next, a break-up into short lengths or dense rectangular segments.

Frequently the MEF terminated as "elastic networks" (MEFC) presumed to be due to localized removal of elastomucin. The "core" of the MEF was indistinguishable from elastin; if covered by a moderate quantity of amorphous material, it appeared "solid" with a "longitudinal grain" (Fig. 5, overleaf) or flat and membranous (Fig. 6, overleaf). If free from elasto-mucin, it was typical filamenting "elastin". Fig. 18 (overleaf, p. 47) shows a good example of an intermediate stage still bearing finelystriated filaments. The picture described was demonstrated very clearly in hundreds of fields on the microscopic screen, but proved very difficult to photograph adequately as each structure frequently stretched across several fields. No collagen and only extremely scanty fine threads were seen throughout this control series. 
The scale marked on all the figures represents $1 \mu$ and all the preparations have been shadowed with chromium.

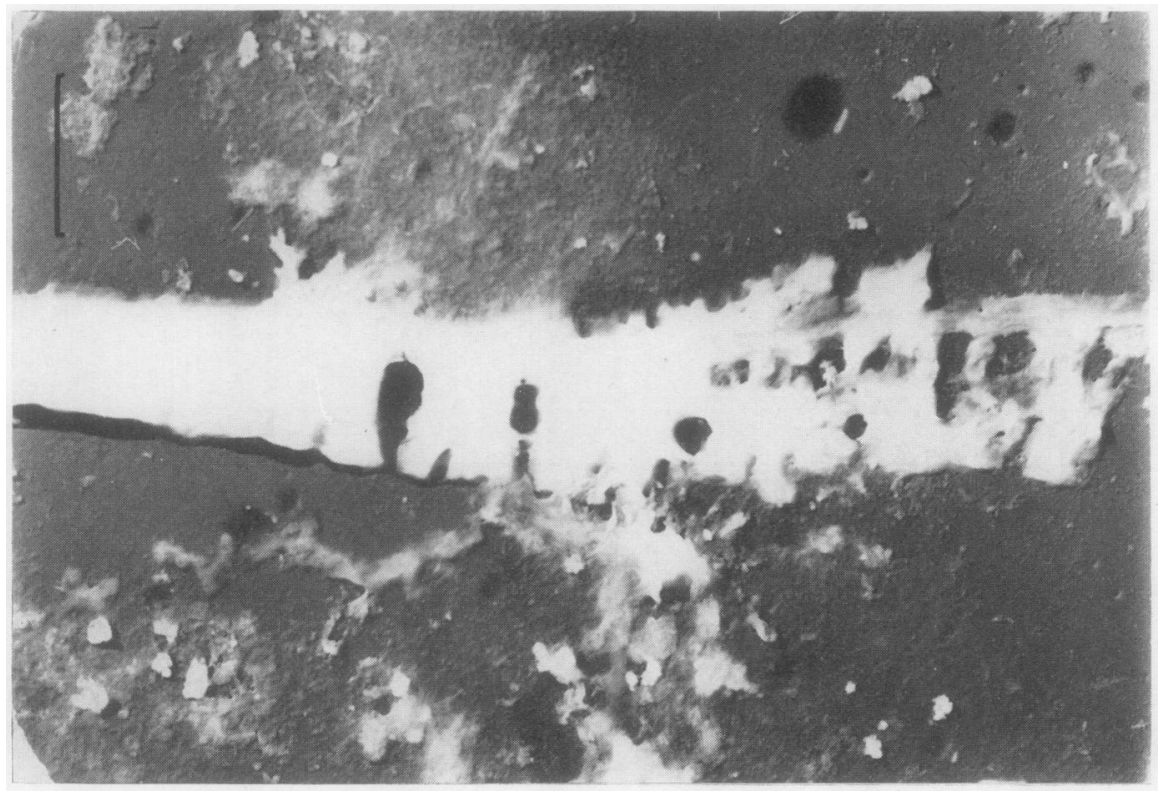

Fig. 1._-"Moth-eaten" fibre (MEF) starting material: prepared abdominal skin collagen from a 2-yr-old child after incubation with collagenase $(\mathrm{Cl}$. histolyticum $)$ for $24 \mathrm{hrs}$ at $37^{\circ} \mathrm{C}$. A "moth-eaten" fibre mixed with amorphous debris, beaded fibrils, and "beads".

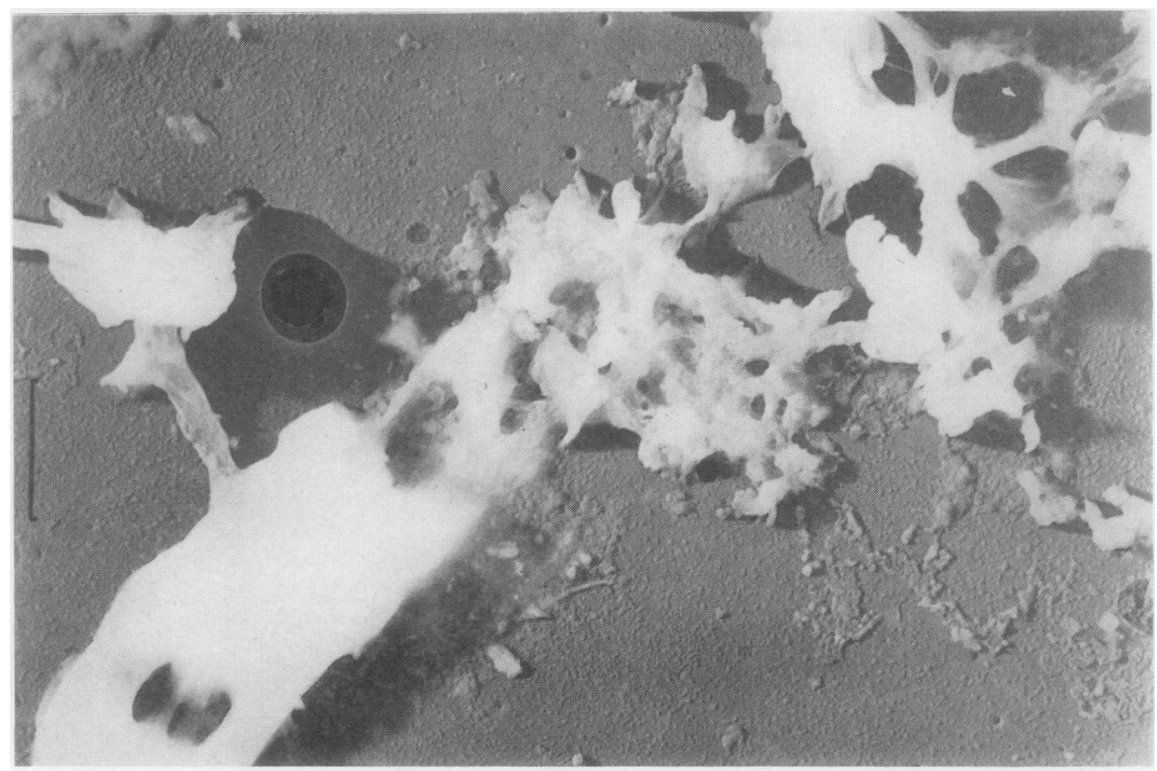

Fig. 2.-Same as Fig. 1, showing an MEF breaking up into an "elastic network" (MEFC). 


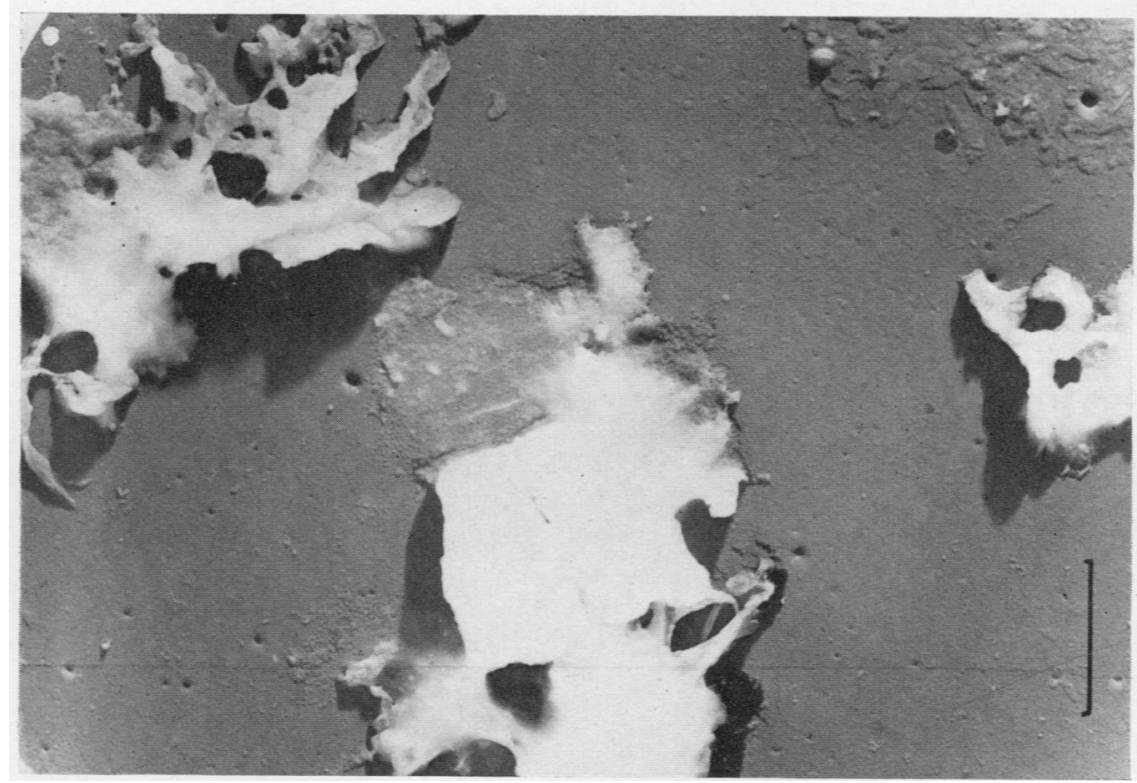

Fig. 3.-Effect of borate buffer ( $p \mathrm{H} \mathrm{8.8)}$ alone on the preparation of MEF. After 3 hrs' incubation at $37^{\circ} \mathrm{C}$. this MEF shows disintegration into a localized mass of "beads". The latter presumably represents the remains of the segment which originally linked the elastic network in the corner of the picture to the main MEF.

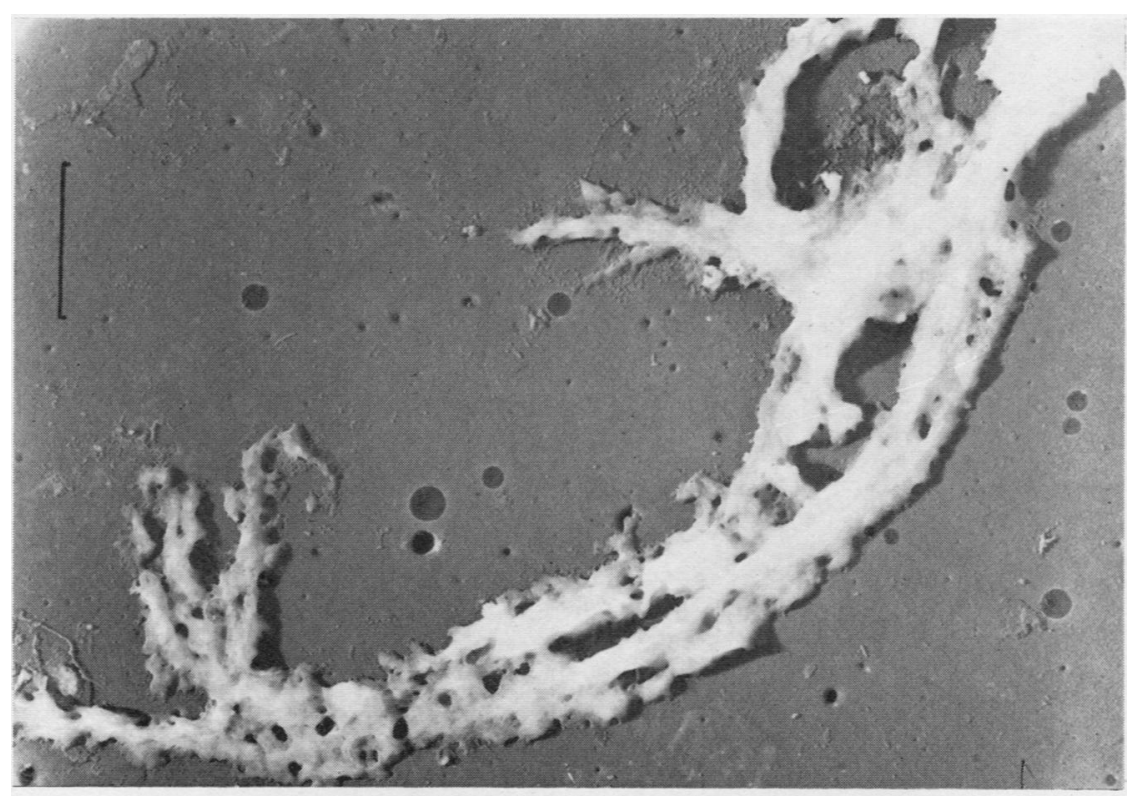

Fig. 4.-Same as Fig. 3 after incubation for 12 hrs at $37^{\circ} \mathrm{C}$. MEF thinner and more disintegrated. Note beaded fibrils and "beads". 


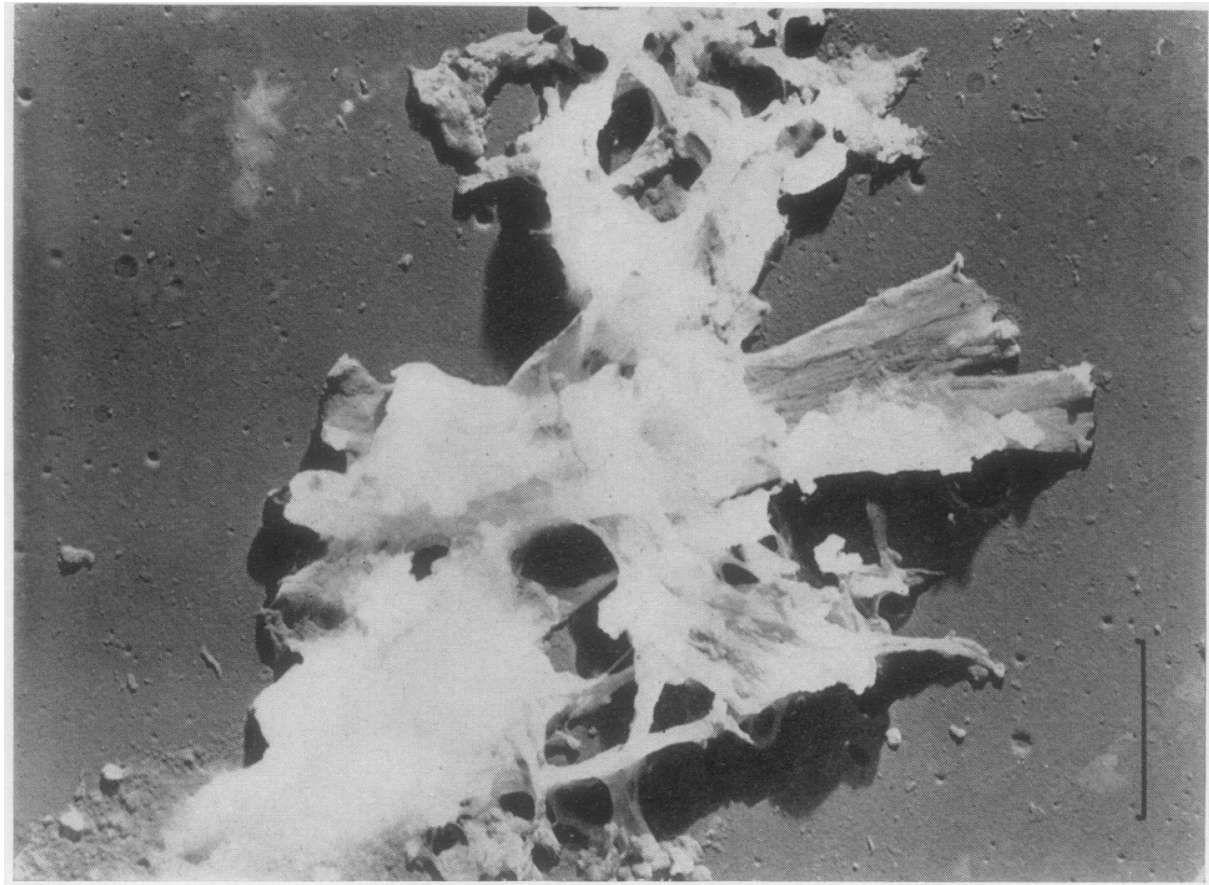

Fig. 5.-Same as Fig. 4 after incubation for 24 hrs at $37^{\circ} \mathrm{C}$., showing the components of a fragmented MEF: a "core" of "solid" elastin and "elastic networks" mixed with dense amorphous material (elastomucin).

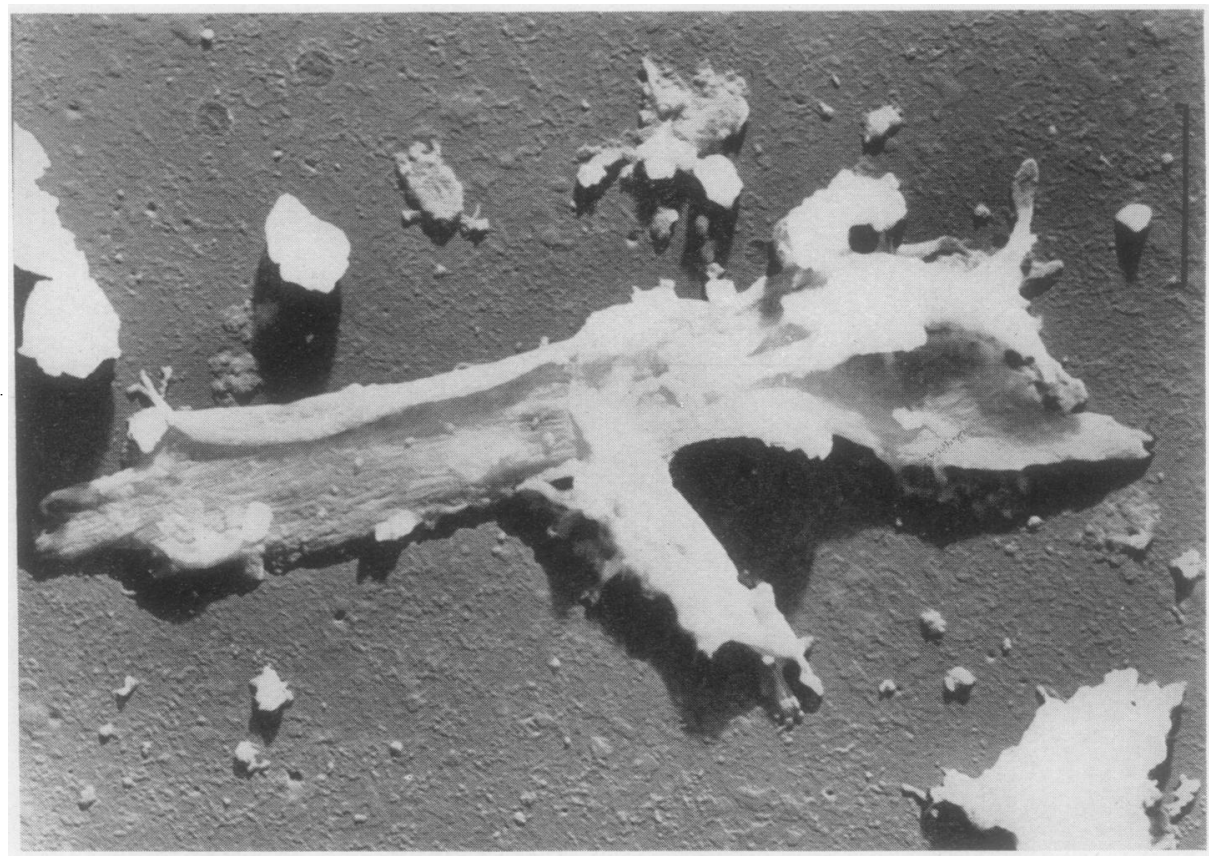

Fig. 6.-Same as Fig. 5, showing a flatter, more membranous type of MEF "core" due to the smaller quantity of associated elastomucin. 


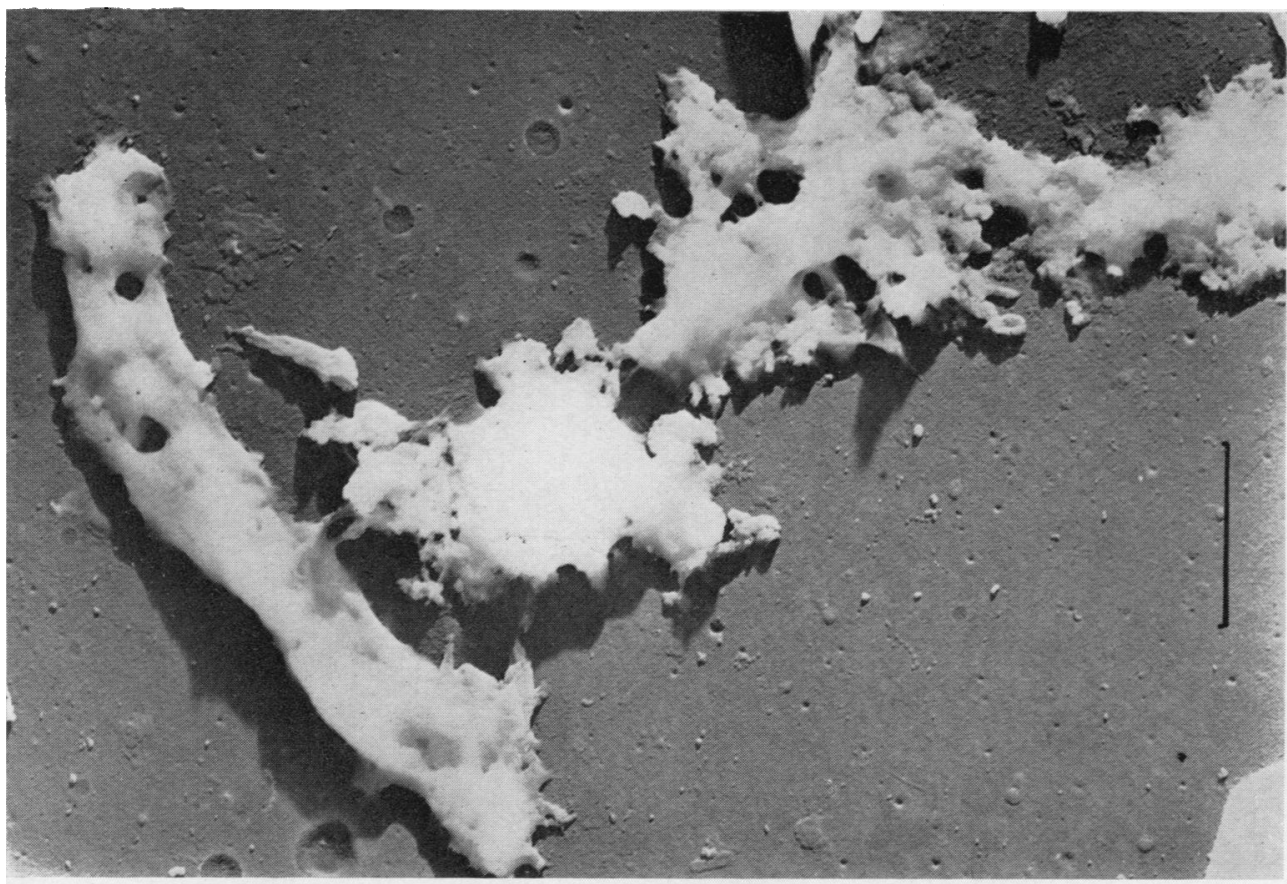

Fig. 7.-Same as Fig. 5, demonstrating the breakdown of an MEF to amorphous material.

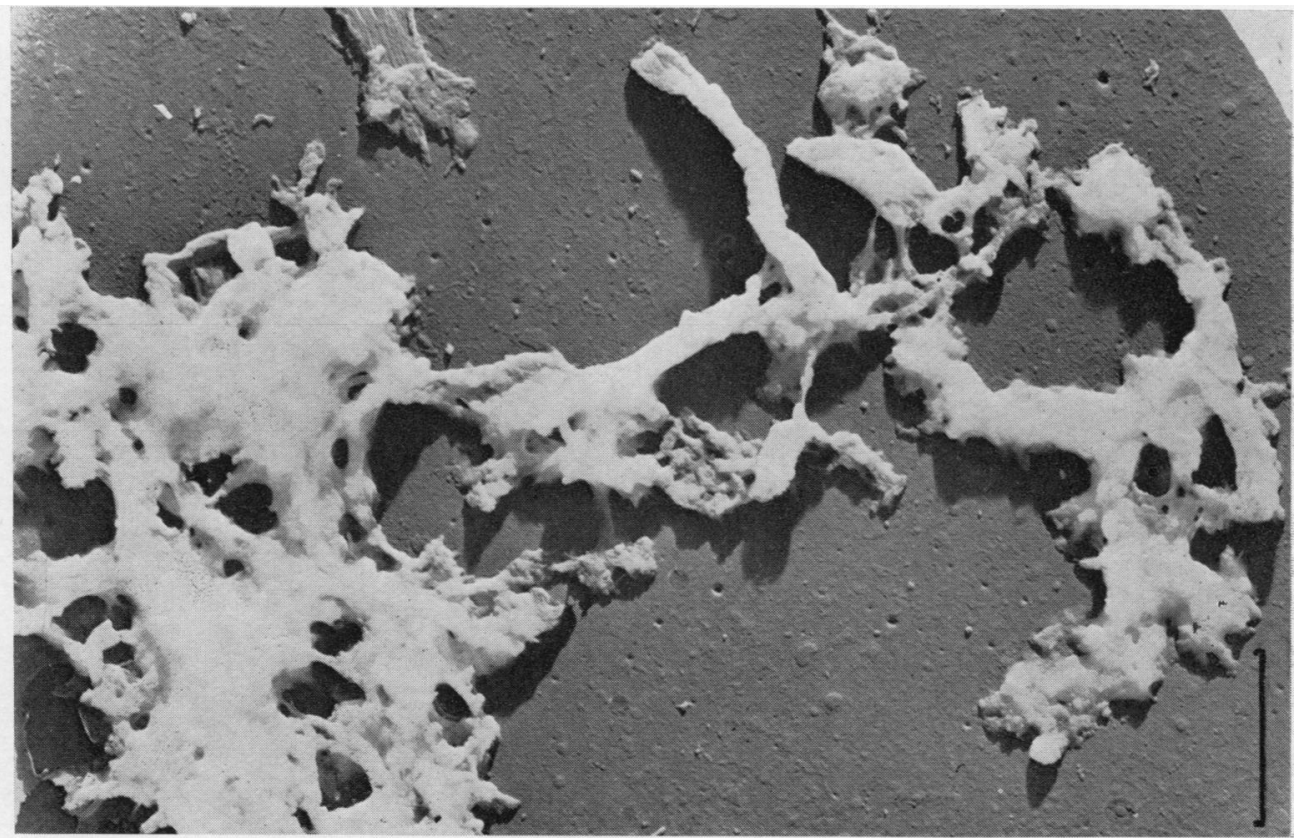

Fig. 8. -Same as Fig. 5, showing the end-product of MEF breakdown: a large "elastic network'. 
Effect of Elastase at $p \mathrm{H} 8 \cdot 8$ on $M E F$.-This series was very different from the controls, the enzyme producing rapid destruction of the MEF to "elastic networks" which were then rapidly digested. After 3 hrs' incubation, no unaltered MEF remained, and the deposit consisted of "elastic networks", dense fibres terminating as "elastin" (MEFC), long ribbons of "filamenting elastin", amorphous material, dense bits, beaded fibrils, and "beads" (Figs 9 and 10). At 12 hrs, examination of 1,250 fields

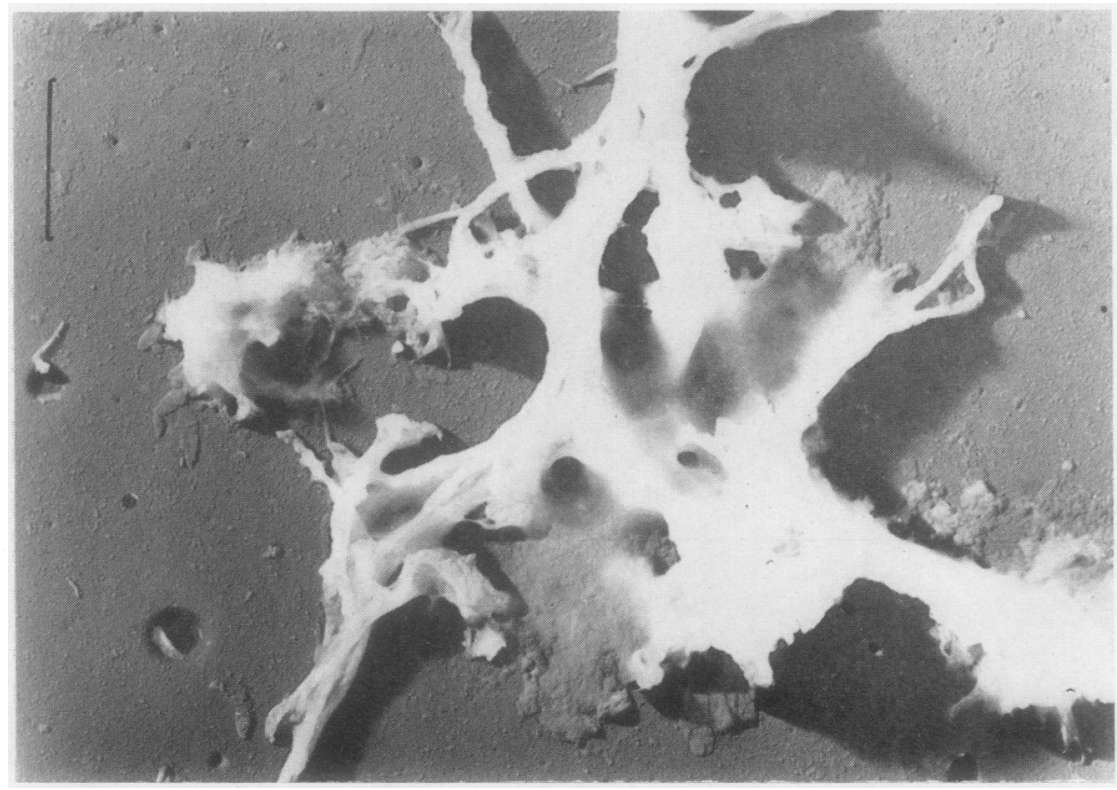

Fig. 9.-Effect of elastase on MEF after incubation for $3 \mathrm{hrs}$ at $37^{\circ} \mathrm{C}$. Long strands of "elastin" closely associated with dense segments disintegrating into amorphous material.

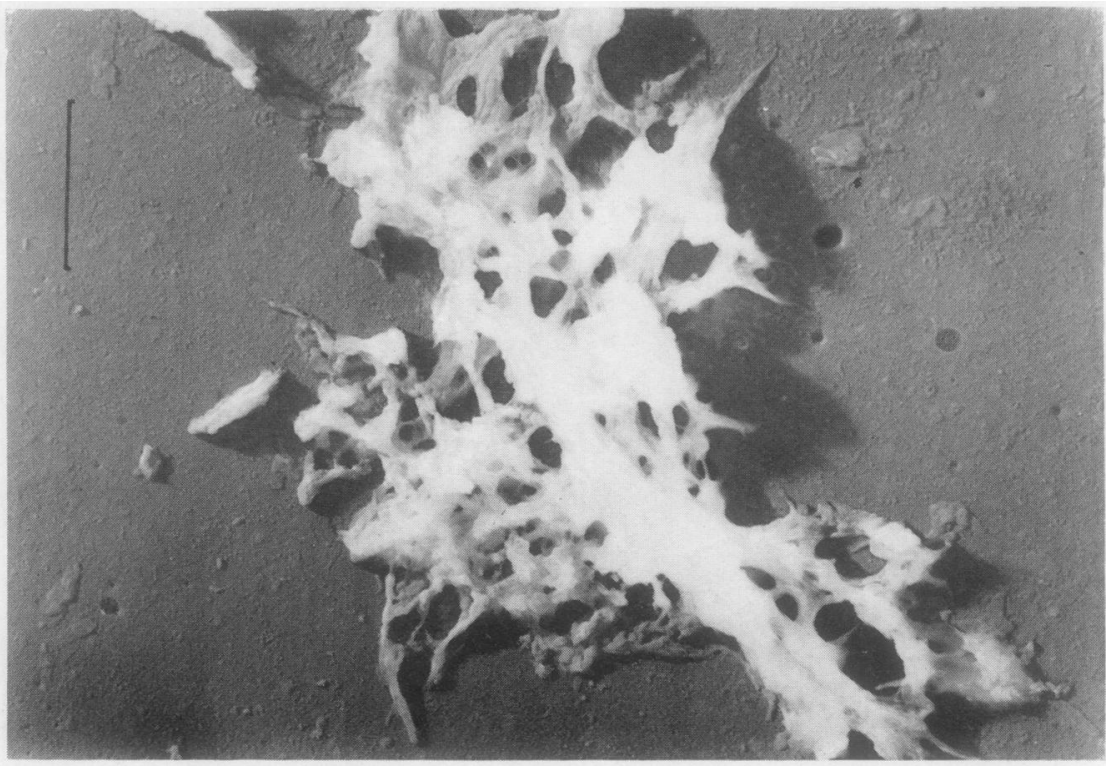

Fig. 10.-Same as Fig. 9, showing a typical "elastic network". 
revealed only twenty tiny remains of "elastic networks" and four degenerate pieces of "elastin" which presented a plaque-like appearance (Fig. 11).

Again after $24 \mathrm{hrs}$, there were a few, very small undigested "networks" (Fig. 12) and short pieces of "filamenting elastin".

No collagen was seen throughout, and fine threads were virtually absent.

Fig. 11.--Same as Fig. 9, after incubation for $12 \mathrm{hrs}$ at $37^{\circ} \mathrm{C}$. An example of the scanty degenerate "elastin" presenting a plaque-like appearance.
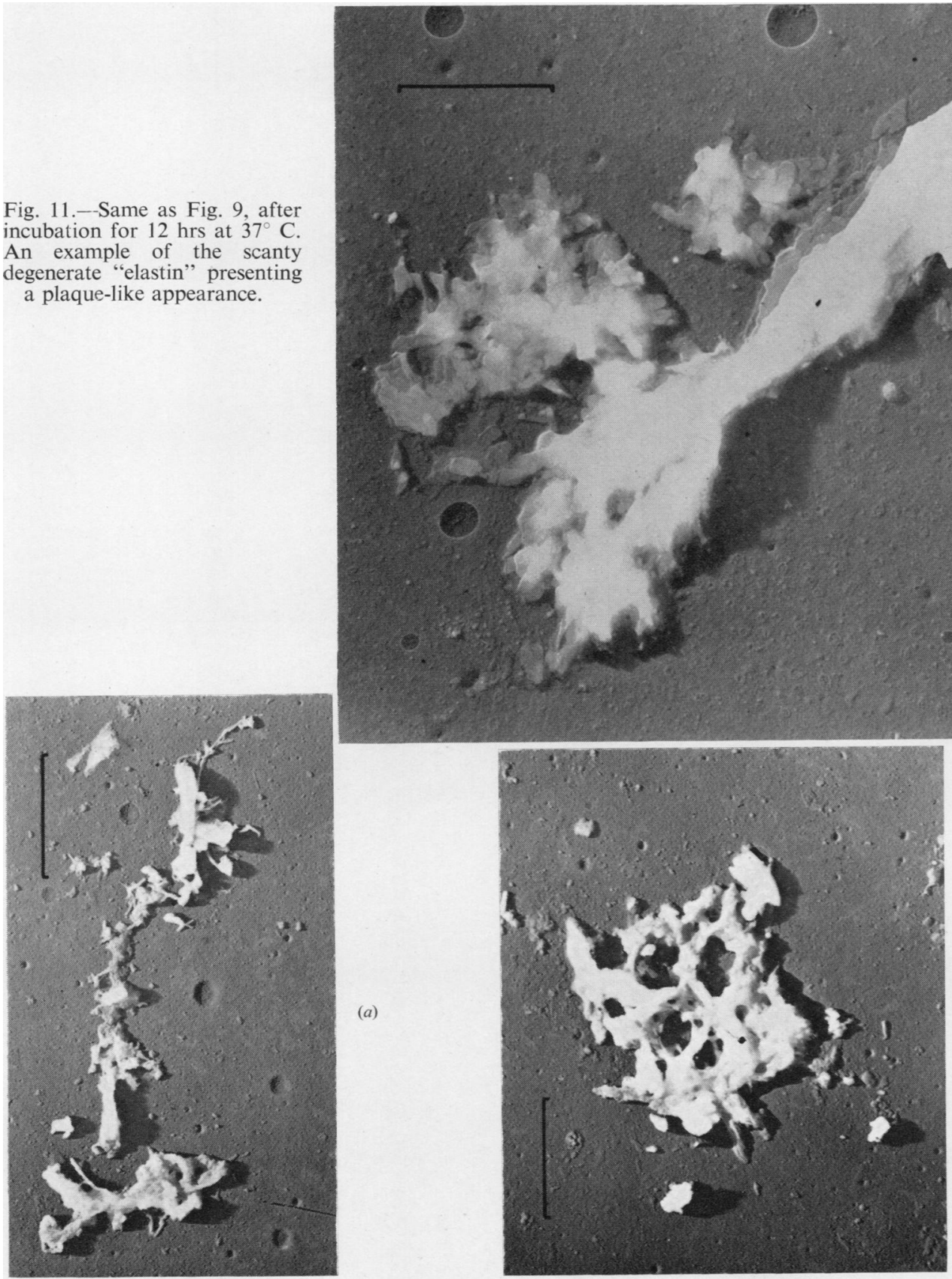

Fig. 12(a) and (b).-Two areas of the same preparation after $24 \mathrm{hrs}$ ' incubation with elastase at $37^{\circ} \mathrm{C}$., showing the tiny undigested remnants of MEF. 
These results should be considered in conjunction with the short-term experiment reported previously (Keech and others, 1956), using the same 2-year-old substrate, in which a dramatic change from MEF to large "elastic networks" occurred after $6 \mathrm{hrs"}$ incubation with elastase.
Effect of Collagenase on MEF.-This enzyme slowly destroyed the MEF at $37^{\circ} \mathrm{C}$. without producing as many "elastic networks" as the experiments reported above. However, unlike the studies at $p \mathrm{H} 8 \cdot 8$, beaded fibrils, "beads", and fine threads were abundant throughout. After 3 hrs' incubation,

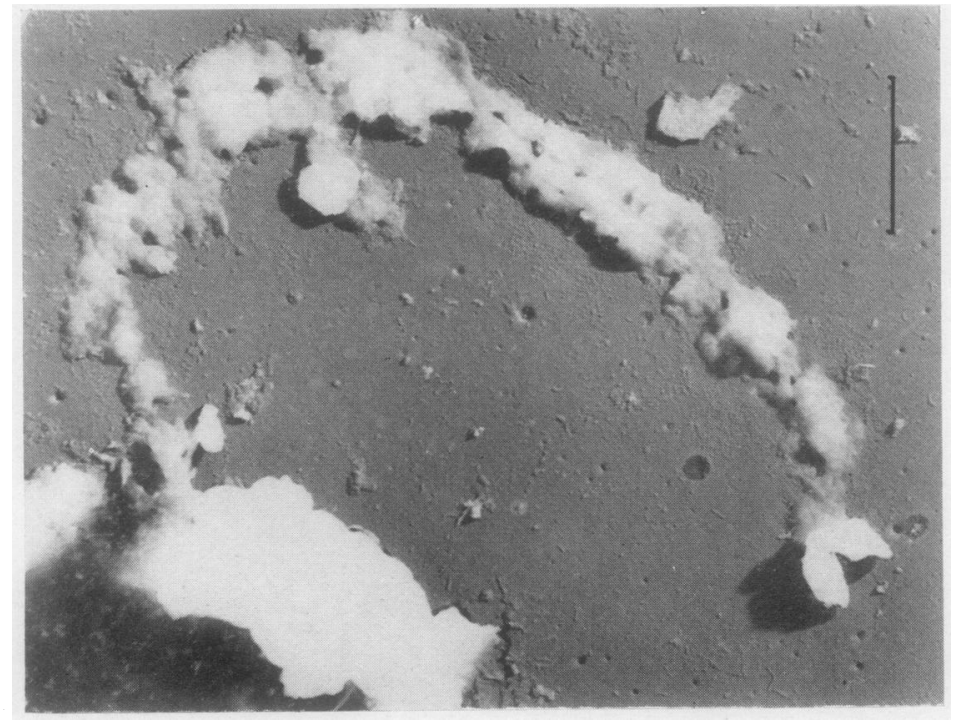

Fig. 13.-Effect of collagenase on MEF after $3 \mathrm{hrs}$. incubation at $37^{\circ} \mathrm{C}$. MEF starting to break down, demonstrating reduction of dense coating of amorphous material and disintegration into "beads". Note the typical fine, thread-like structures scattered at random throughout.

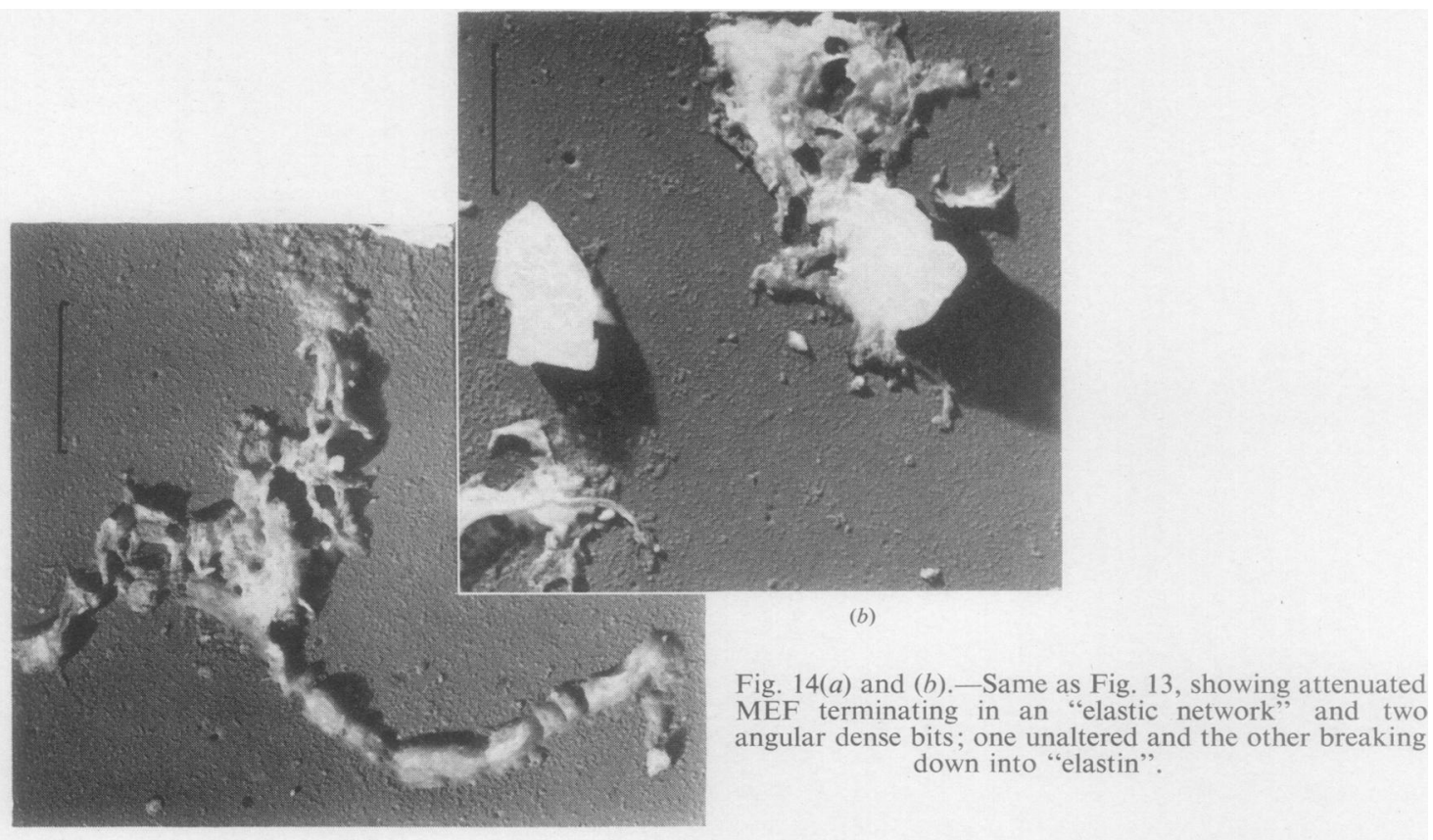

(a) 
MEF were seen in all stages of breakdown (Figs 13-15), and again the long streamers of filamenting "elastin" forming the "core" of the MEF were clearly demonstrated on the screen. At $6 \mathrm{hrs}$ the deposit consisted chiefly of breakdown productsangular dense bits, amorphous material, small "elastic networks", beaded fibrils, "beads", and fine threads.

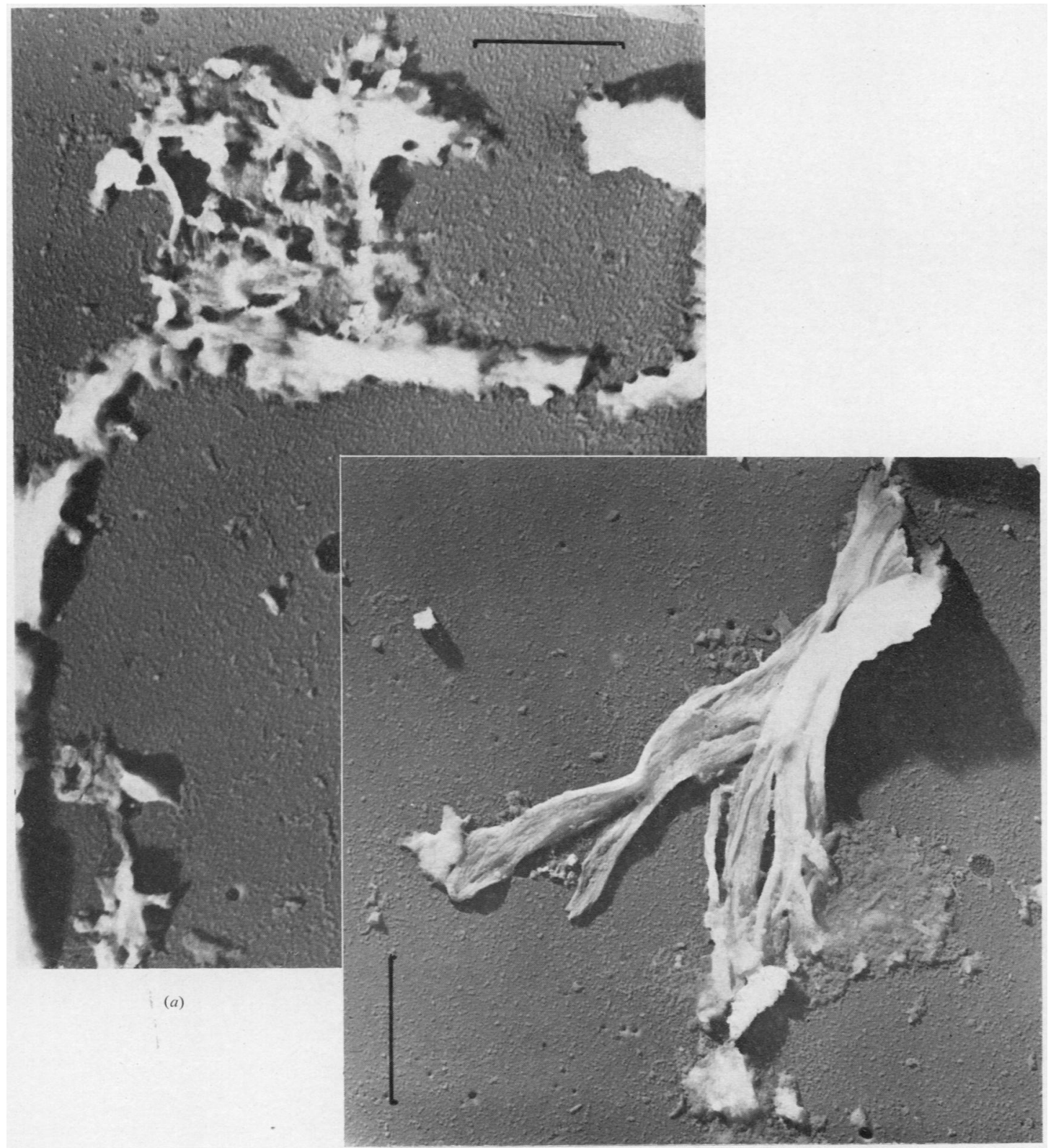

(b)

Fig. 15(a) and (b).-Same as Fig. 13. A disintegrated MEF and an isolated "core" of "solid" elastin. 


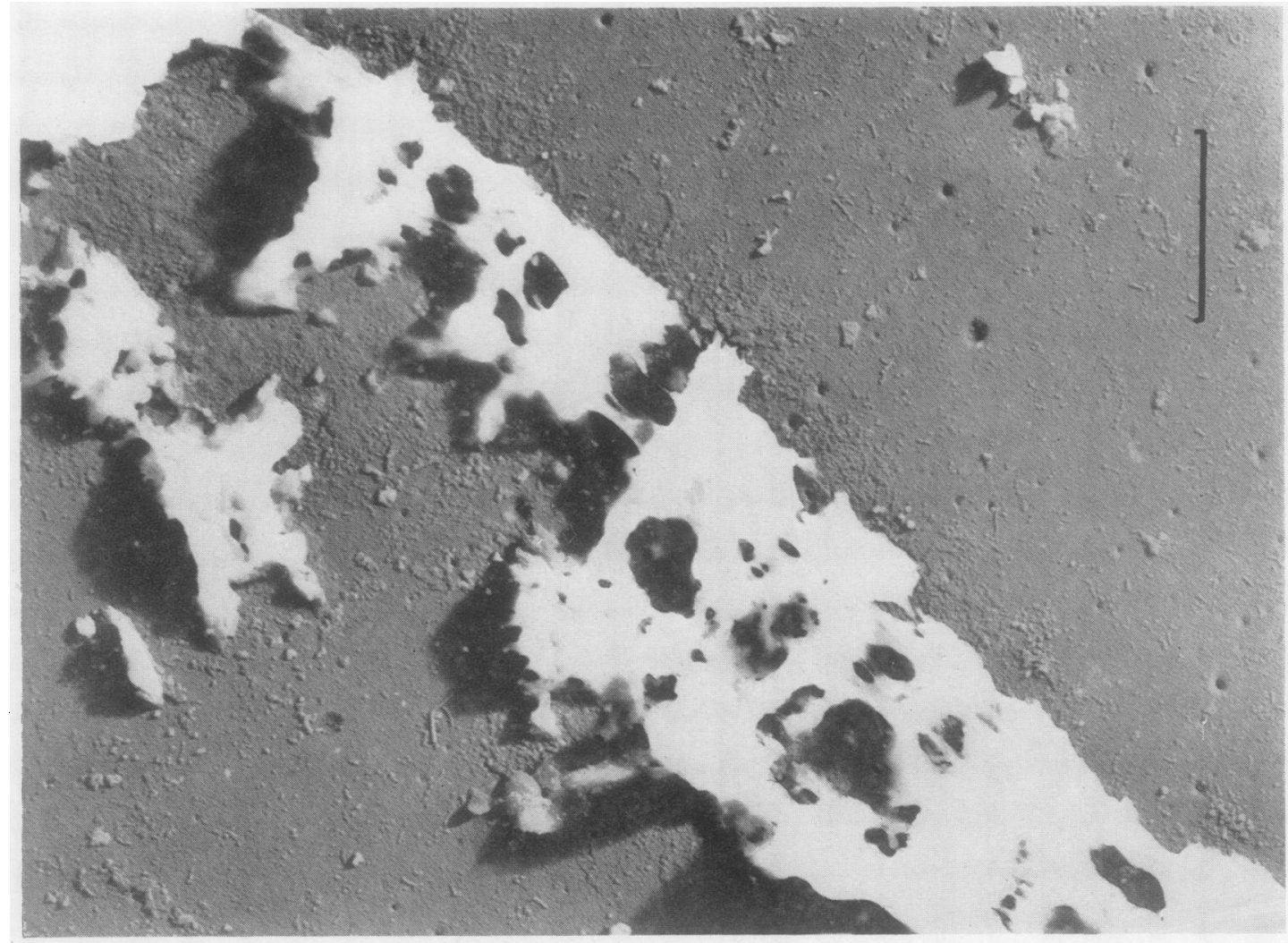

Fig. 16.-Same as Fig. 13 after 6 hrs. incubation at $37^{\circ} \mathrm{C}$. Disintegrating MEF with large "moth-holes" containing masses of "beads". Note the scattered fine threads.

The few remaining MEF had larger "moth-holes" and were disintegrating (Fig. 16).

At 12 hrs (Fig. 17, opposite) the picture was essentially the same, and scanty typical MEF were seen.

Effect of Ultrasonic Radiation (22 Kc. at $25^{\circ}$ C.) on $M E F$.-This 30-minute treatment produced definite breakdown of the MEF to their component "elastin" and amorphous material (Figs 19 and 20, overleaf).

The MEF were fragmented to short lengths, some terminating as "elastin" (MEFC), and others remaining isolated, rectangular segments. There was a moderate quantity of "filamenting elastin", much granular amorphous material, and many beaded fibrils and "beads", but fine threads were virtually absent.

Effect of Hyaluronidase on MEF.-Hyaluronidase also produced MEF breakdown to reveal their component parts. After $90 \mathrm{~min}$. some of the MEF were fragmented to form MEFC, being mixed with "filamenting elastin", angular dense bits, and granular amorphous material. However, quite a number remained relatively unaltered (Fig. 21, overleaf).

By 3 hrs, however, every MEF was modified, and breaking down either into amorphous material and angular dense bits, or "elastic networks" (Figs 22-25, overleaf).

The 6-hr picture was very similar, and again long streamers of "filamenting" or the "solid" type of the elastin-like material described above appeared to be forming the "core" of the disintegrating MEF. The structures in the 24-hr deposit were noticeably smaller than at $6 \mathrm{hrs}$, and represented the final remnants of the MEF. Scanty collagen was present in all the samples (the starting material was the batch containing a very small quantity of collagen), usually mixed with amorphous material and showing little or no evidence of "standard" collagenase change. 


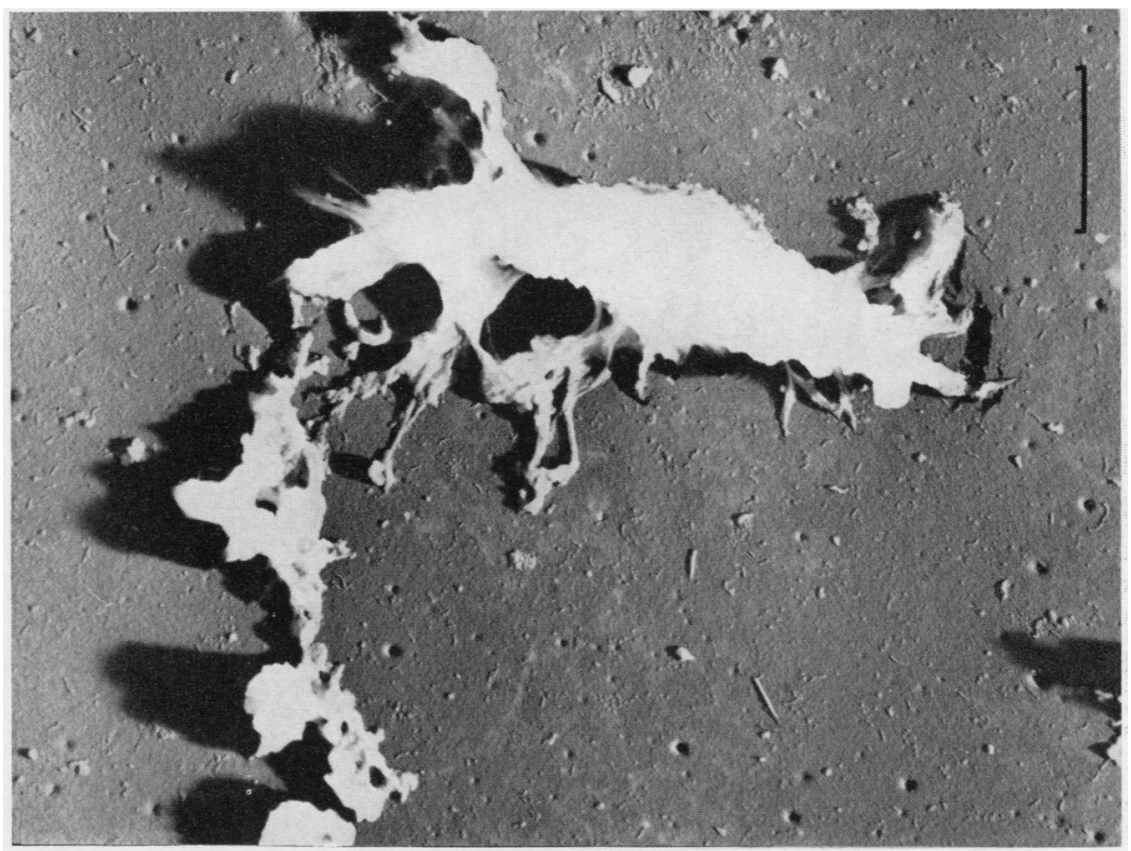

Fig. 17.- Same as Fig. 13 after $12 \mathrm{hrs}$. incubation at $37^{\circ} \mathrm{C}$., showing an elastic "core" and remains of MEF segments. Note the scattered fine threads, some moderately long. and thick, and others short and thin.

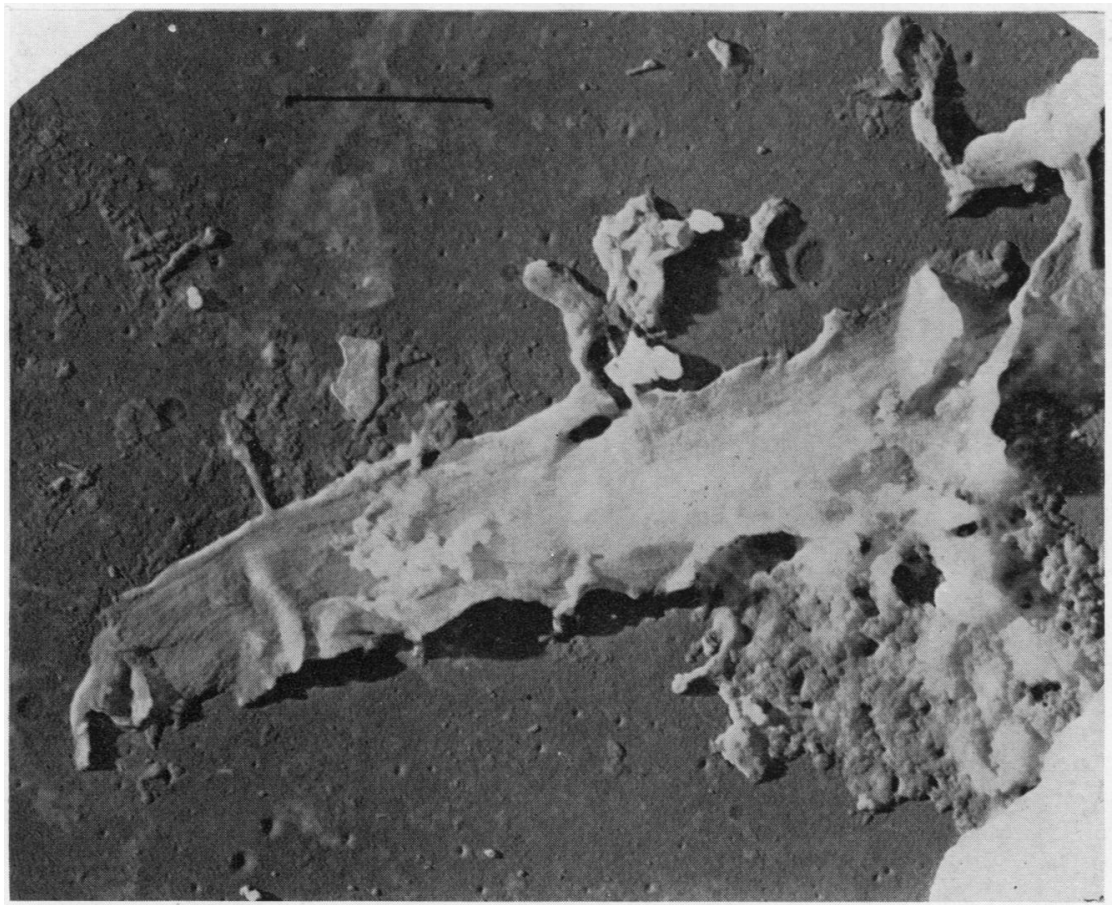

Fig. 18.-A piece of filamenting "elastin" seen after $24 \mathrm{hrs'} \mathrm{incubation} \mathrm{with} \mathrm{borate} \mathrm{buffer}$ $(p \mathrm{H} 8 \cdot 8)$ alone at $37^{\circ} \mathrm{C}$. The areas free of elastomucin show finely striated filaments. 


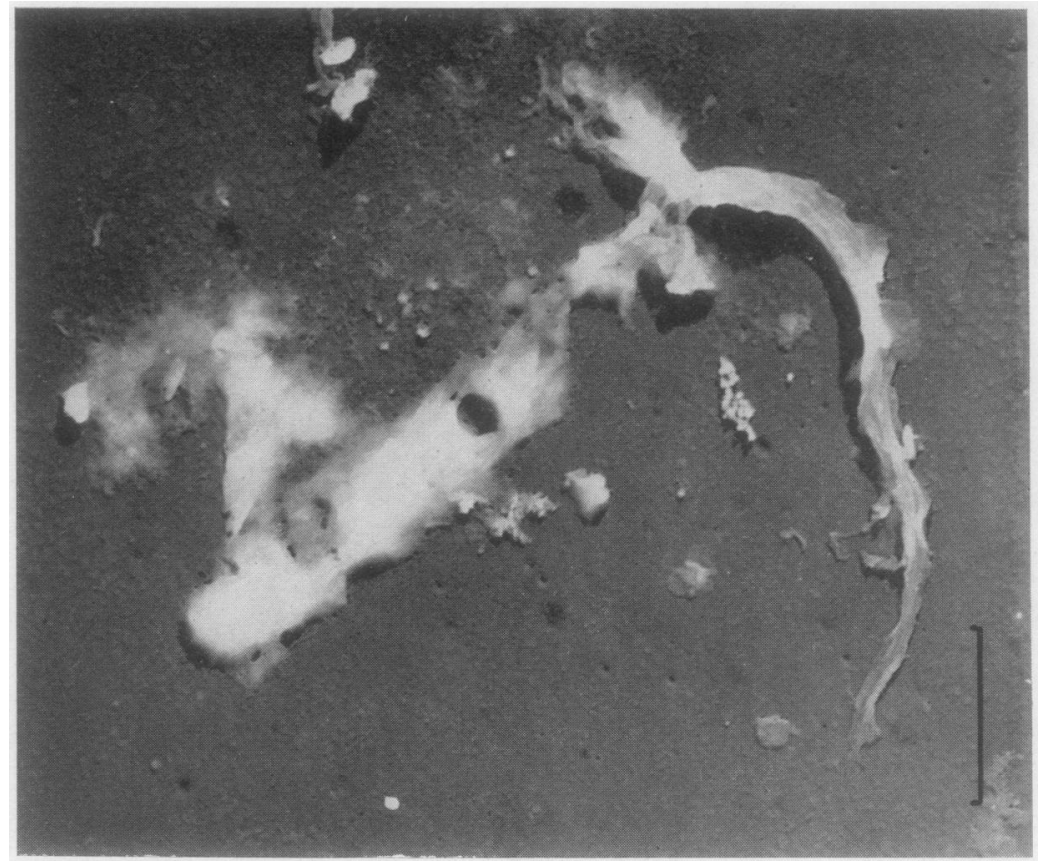

Fig. 19.-Effect of ultrasonic radiation for $30 \mathrm{~min}$. at $25^{\circ} \mathrm{C}$. on the preparation of MEF produced fragmentation into short lengths, some terminating as "elastin".

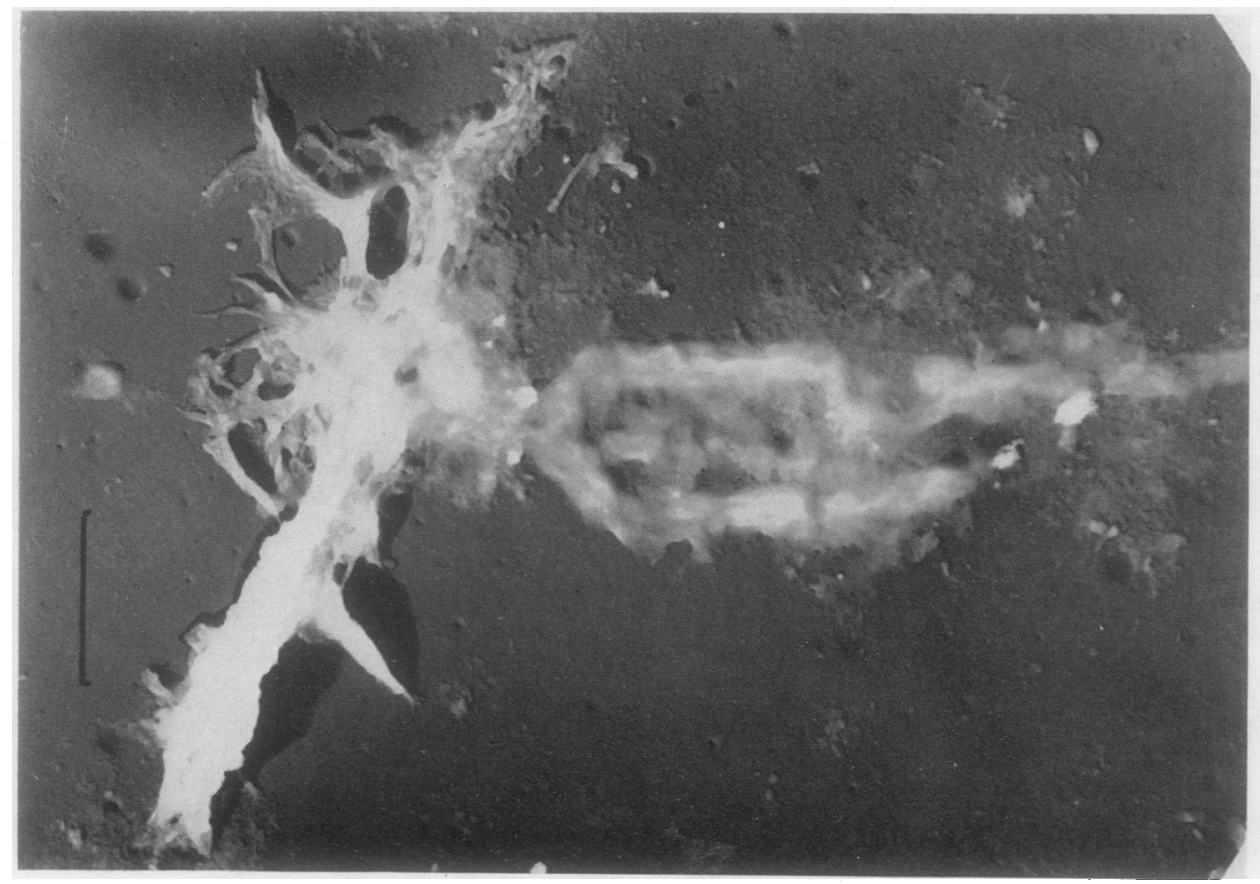

Fig. 20.-Same as Fig. 19, showing reduction in the dense coating of amorphous material as well as break down to "elastin". Note beaded fibrils in top left corner. 


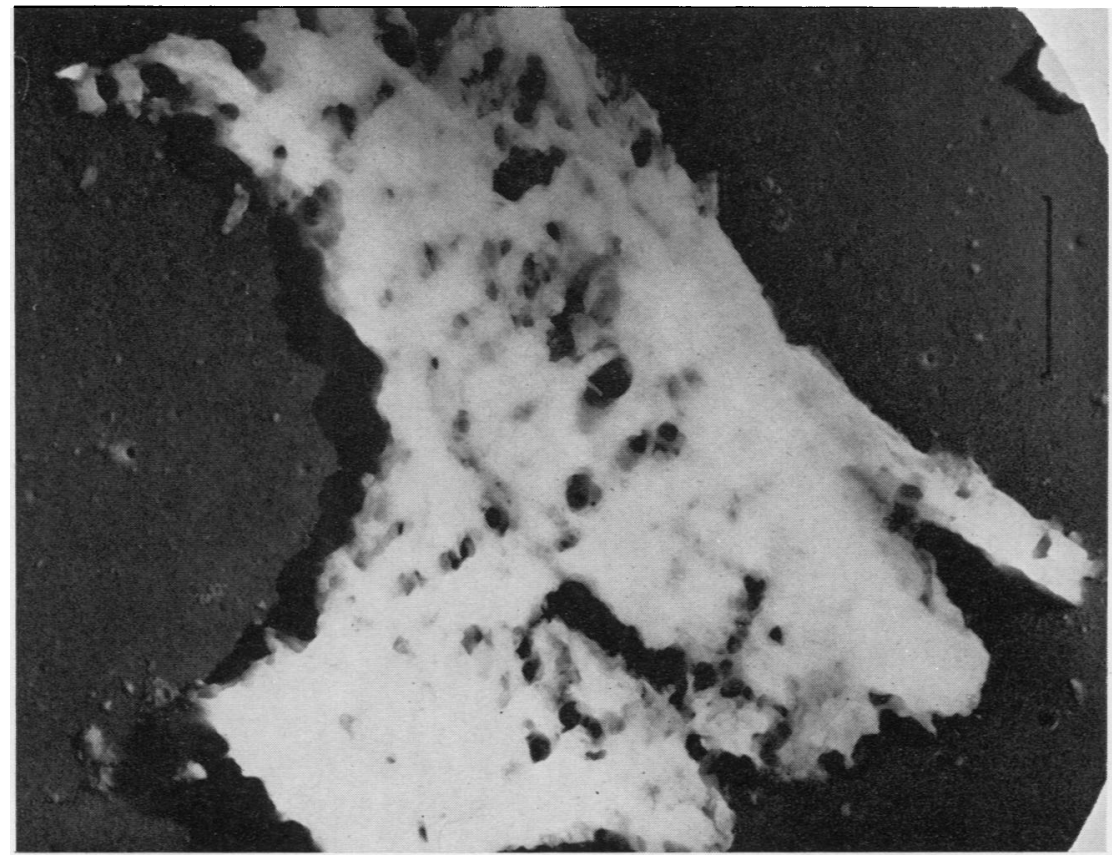

Fig. 21.-Effect of hyaluronidase on MEF. After incubation at $37^{\circ} \mathrm{C}$. for $90 \mathrm{~min}$., quite a number of the MEF remained relatively unaltered.

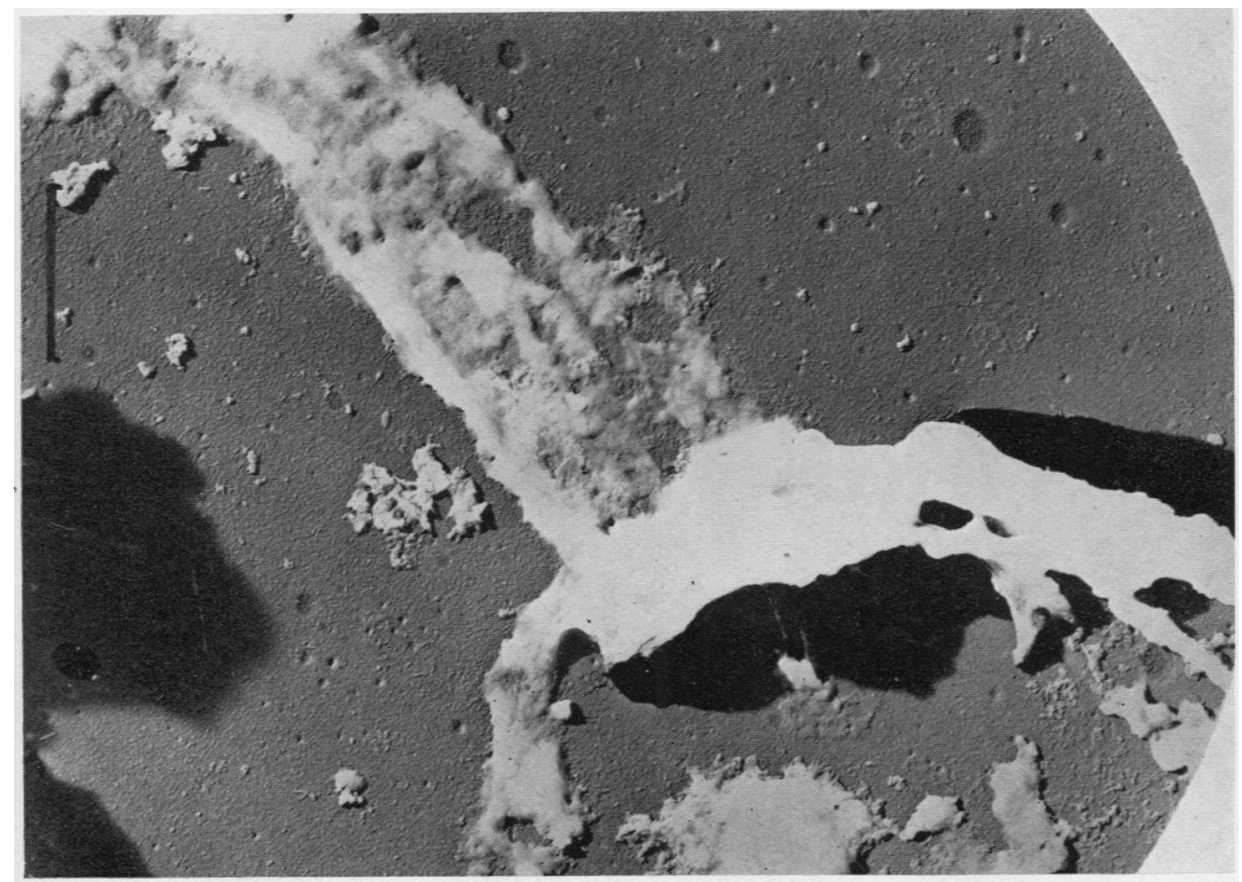

Fig. 22.-Same as Fig. 21 after $3 \mathrm{hrs}$. incubation at $37^{\circ} \mathrm{C}$., showing a disintegrating MEF. 


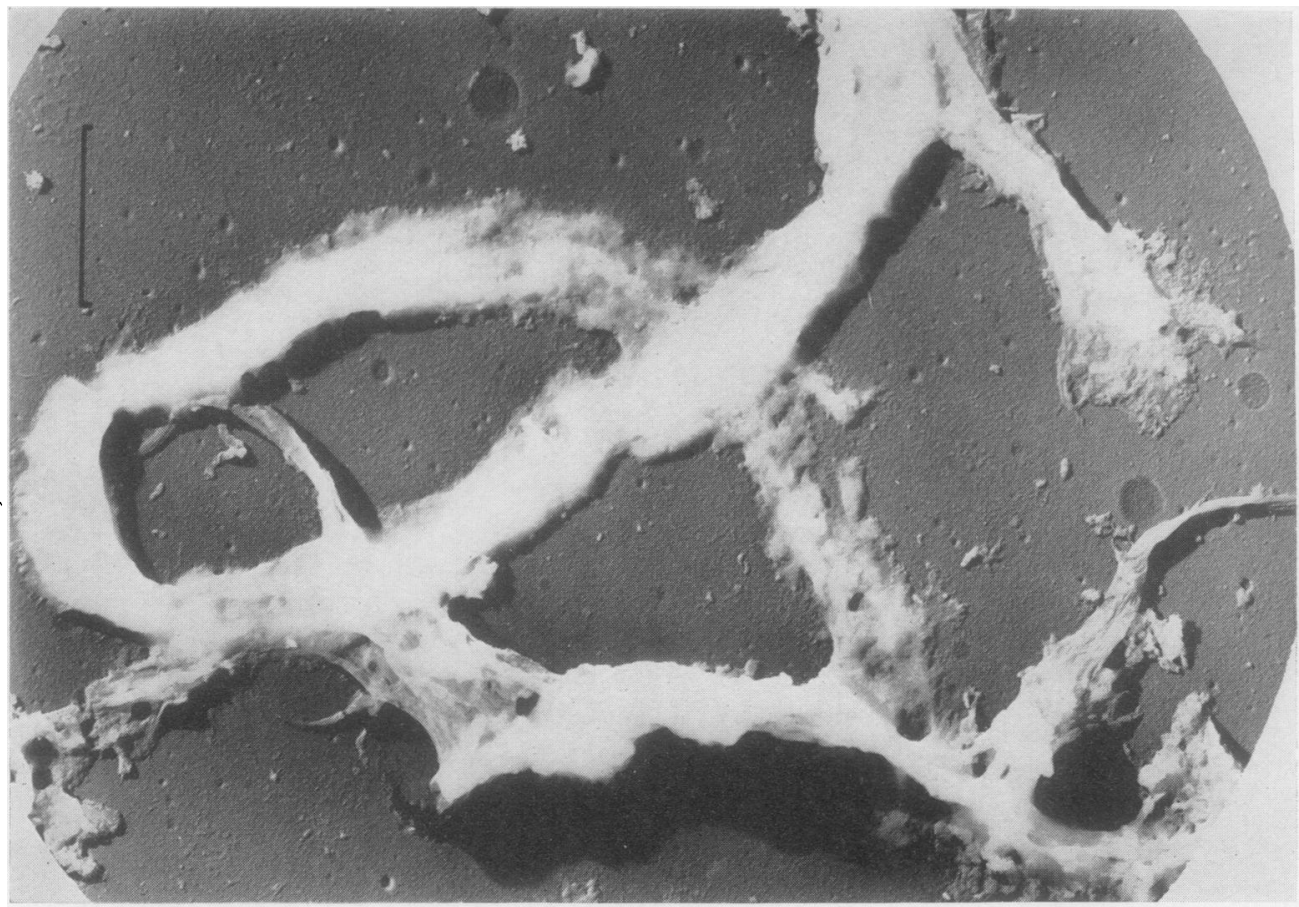

Fig. 23. - Same as Fig. 22, showing MEF terminating as a long ribbon of "elastin" partially coated with dense amorphous material (elastomucin).

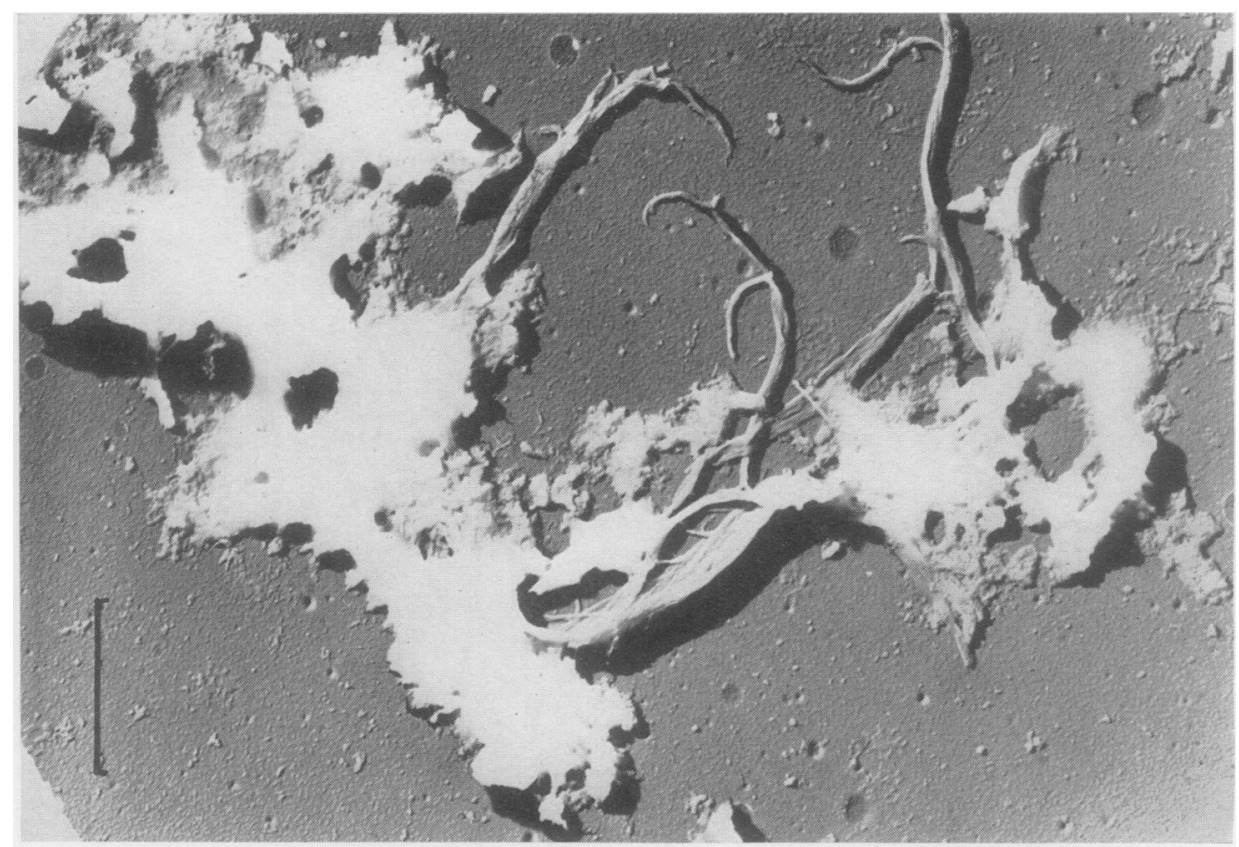

Fig. 24.-Same as Fig. 22, showing breakdown to thin filaments of "elastin" free of amorphous material. 


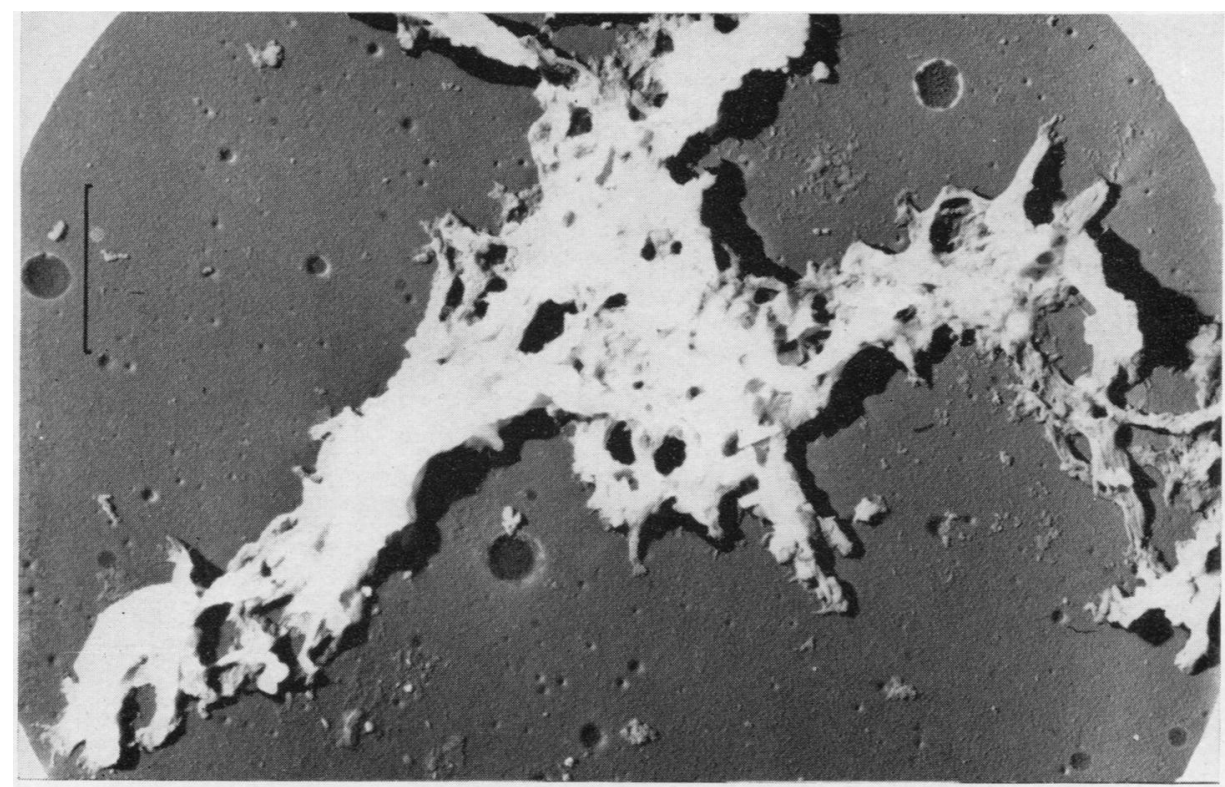

Fig. 25.-Same as Fig. 22, showing breakdown to "elastic networks".

Although the counts (solitary fibrils as well as groups) were two to four times greater than in the starting material, it is difficult to judge whether or not this is significant. Occasionally photographs could be taken showing the possible occurrence of collagen fibrils in the centre of the MEFs (Fig. 26). The absence of fine threads was remarkable.

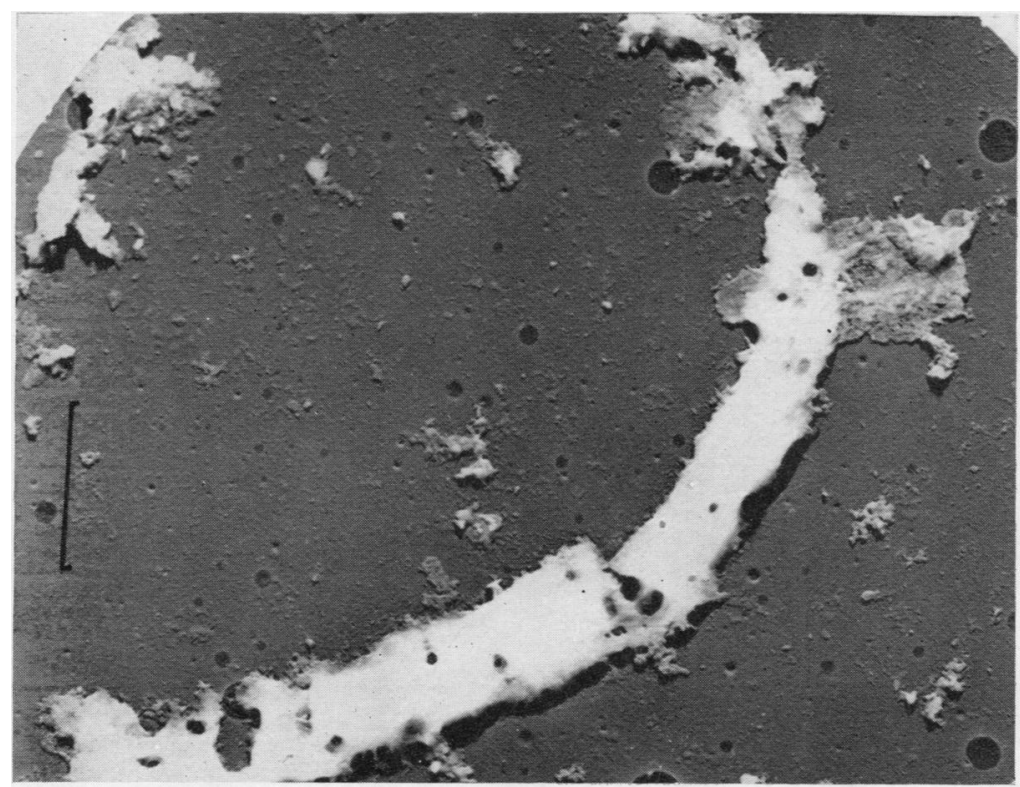

Fig. 26.-Same as Fig. 22 after 24 hrs' incubation at $37^{\circ} \mathrm{C}$., demonstrating collagen as a possible MEF "core". 


\section{(B) Preparations of Elastin (Table II)}

Effect of Heat alone on the Elastin Substrate.-No significant change was found to follow the treatment described above. The substrate remained the same as the starting material (Figs 27 and 28, opposite), which consisted of:

(a) Numerous, large, dense fibres, frequently so large that they broke the collodion membrane covering the electron microscope grid. Some had smooth edges but the majority had "fluffy" outlines, splaying out into either amorphous material or typical elastic networks.

(b) Numerous large and small angular dense bits, usually clear-cut but some in the process of transformation into elastin.

(c) A little typical fully-formed elastin (skin-type, filamenting, and large natural networks) which was separate from the other structures described.
No collagen was seen.

Effect of Phosphate Buffer alone ( $p \mathrm{H}$ 7.3) on Elastin.-The elastin substrate remained typical and unaltered throughout. Collagen was absent, and fine threads were extremely scanty. A careful examination did not reveal any MEF whatsoever.

Effect of Collagenase on Elastin.-After $24 \mathrm{hrs}$ the substrate was more broken up, and there was an increase in fully-formed elastin. Collagen was absent and fine threads were extremely scanty. There were a few structures somewhat resembling MEF, but they were not typical. A fresh lot of enzyme was added, incubation was continued, and the 35-hr deposit contained, in addition to the typical elastin substrate, a fair number of MEF.

TABLE II

SUMMARY OF THE RESULTS OF EXPERIMENTS PERFORMED ON ELASTIN AT LEAST 1,250 MICROSCOPIC FIELDS WERE EXAMINED AT EACH TIME-INTERVAL

COLlagen-FreE

Ox Ligamentum Nuchae

A fine powder consisting of:

(1) Large dense fibres either smooth-edged, or with fluffy outlines, splaying out into amorphous material or typical elastic networks.

(2) Large and small angular dense bits, either clear-cut or changing into elastin

(3) Small quantity of typical fully-formed elastin.

(4) No collagen.

\begin{tabular}{|c|c|c|c|c|}
\hline Time & HEAT ALONE IN $\mathrm{H}_{2} \mathrm{O}$ & Time & Buffer CoNTrol $(p \mathrm{H} 7 \cdot 3)$ & Collagenase $(p \mathrm{H} \quad 7 \cdot 3)$ \\
\hline$\underset{55^{\circ} \mathrm{C}}{\mathbf{h r}}$ & $\begin{array}{l}\text { Unaltered } \\
\text { No collagen } \\
\text { No MEF } \\
\text { No fine threads }\end{array}$ & $\begin{array}{l}24 \mathrm{hrs} \\
\text { at } \\
37^{\circ} \mathrm{C}\end{array}$ & $\begin{array}{l}\text { Unaltered } \\
\text { No collagen } \\
\text { No MEF } \\
\text { Very very scanty fine threads }\end{array}$ & $\begin{array}{l}\text { Substrate more broken up } \\
\text { Increase in fully-formed elastin } \\
\text { No collagen } \\
\text { No definite MEF } \\
\text { Very very scanty fine threads }\end{array}$ \\
\hline $\begin{array}{l}\text { Further } \\
\text { hr } \\
\text { at } \\
75^{\circ} \mathrm{C} \text {. }\end{array}$ & Same as at $1 \mathrm{hr}$ & $\begin{array}{l}35 \mathrm{hrs} \\
\text { at } \\
37^{\circ} \mathrm{C} \text {. }\end{array}$ & Same as at 24 hours & $\begin{array}{l}\text { FURTHER ENZYME ADDED } \\
\text { In addition to elastin substrate numerous typical } \\
\text { MEF, both unaltered and starting to disintegrate } \\
\text { No collagen } \\
\text { Very very scanty fine threads } \\
\text { Very scanty? reticulin }\end{array}$ \\
\hline \multirow[t]{2}{*}{$\begin{array}{l}\text { Further } \\
\text { hr } \\
\text { at } \\
110^{\circ} \mathrm{C} \text {. }\end{array}$} & Same as at $1 \mathrm{hr}$ & $\begin{array}{l}48 \mathrm{hrs} \\
37^{\circ} \mathrm{Ct}\end{array}$ & Same as at $24 \mathrm{hrs}$ & $\begin{array}{l}\text { Numerous MEF in all stages of breakdown } \\
\text { No collagen } \\
\text { Very very scanty fine threads } \\
\text { Some? reticulin }\end{array}$ \\
\hline & & $\begin{array}{l}3 \text { wks } \\
\text { at } \\
5^{\circ} \mathrm{C}\end{array}$ & Not examined & $\begin{array}{l}\text { MEF in all stages of breakdown } \\
\text { Very very scanty collagen } \\
\text { Very very scanty fine threads } \\
\text { Masses of ? reticulin forming a background network }\end{array}$ \\
\hline
\end{tabular}

MEF = "Moth-eaten" fibres

Fully-formed elastin = skin-type, filamenting, and large networks (Keech, Reed, and Wood, 1956)

Macroscopically the elastin powder heated in $\mathrm{H}_{2} \mathrm{O}$ or in buffer $(p \mathrm{H} 7 \cdot 3)$ appeared unaltered. The collagenase-treated supernatant became progressively opaque, in comparison with the water-clear control, the difference being very marked at 48 hrs

Under the light microscope at 35 and 48 hrs the test deposit was much finer than the control, with large, long, irregular structures in place of the smooth-edged, highly refractile fibres present in both the starting material and the control. 


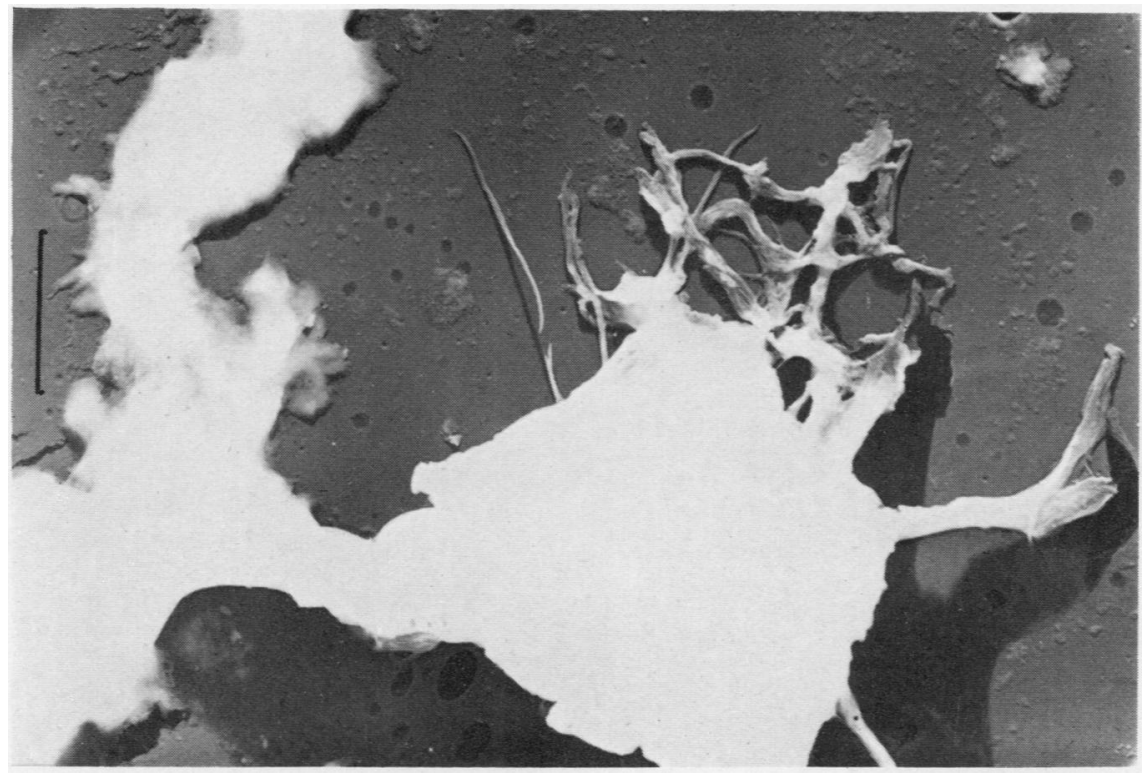

Fig. 27.-Ox ligamentum nuchae elastin starting material. A dense fibre with "fluffy" outline joined to a large, clear-cut dense bit that is partially splayed out into typical elastin.

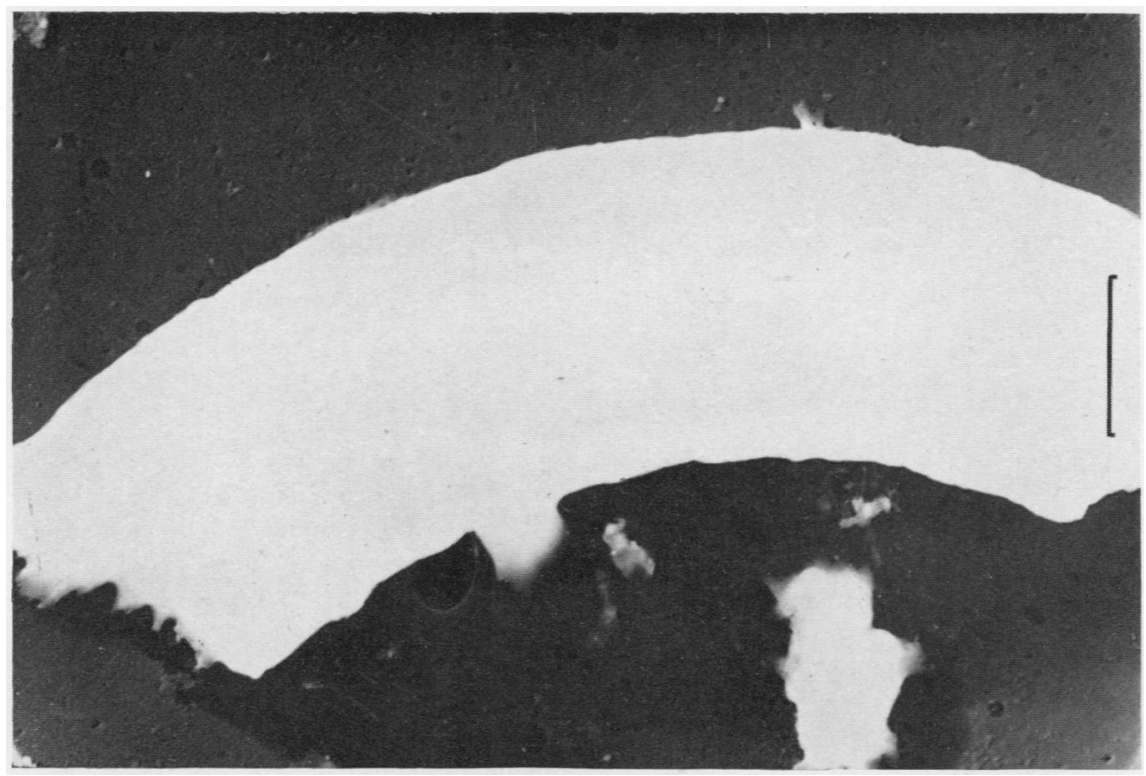

Fig. 28.-Same as Fig. 27, showing one of the characteristic large, very dense fibres that usually broke the collodion membrane covering the electron microscope grid. 
These were either large and unaltered, stretching collodion (Figs 29 and 30), terminating in the across several fields and frequently breaking the so-called elastic networks to form MEFC (Fig.

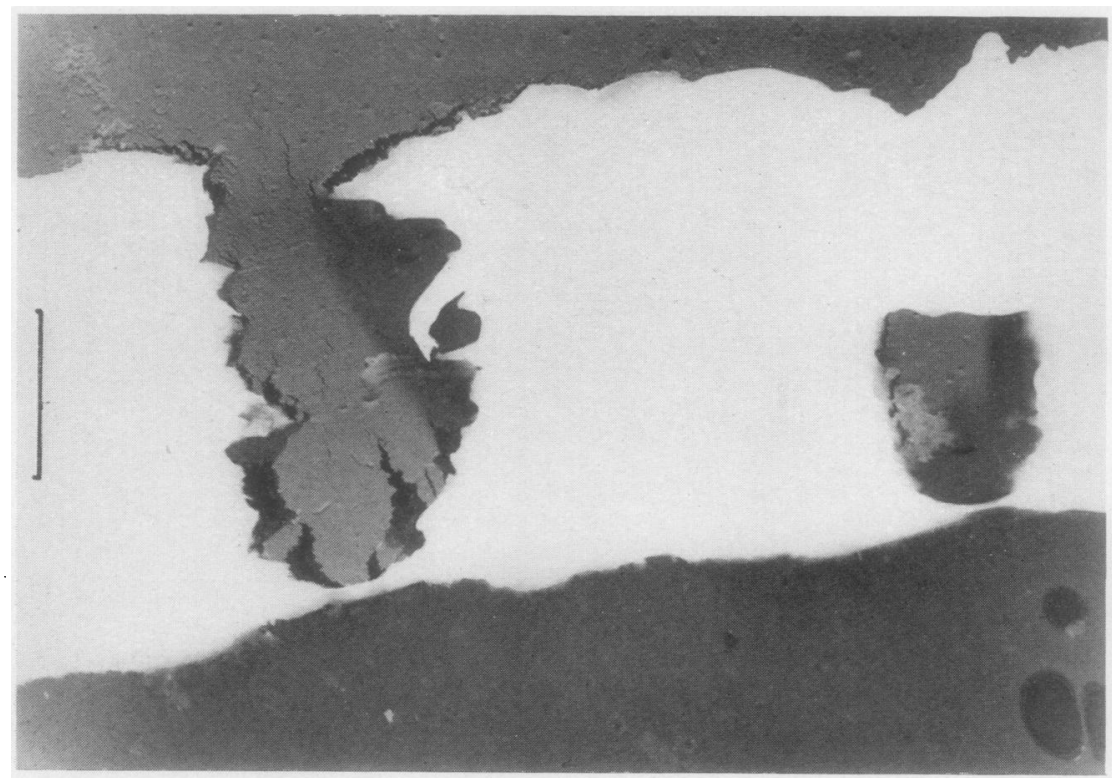

Fig. 29.-Effect of collagenase on elastin. After incubation for $35 \mathrm{hrs}$ ' at $37^{\circ} \mathrm{C}$., the deposit contained a fair number of typical MEF usually stretching across several fields and breaking the collodion.

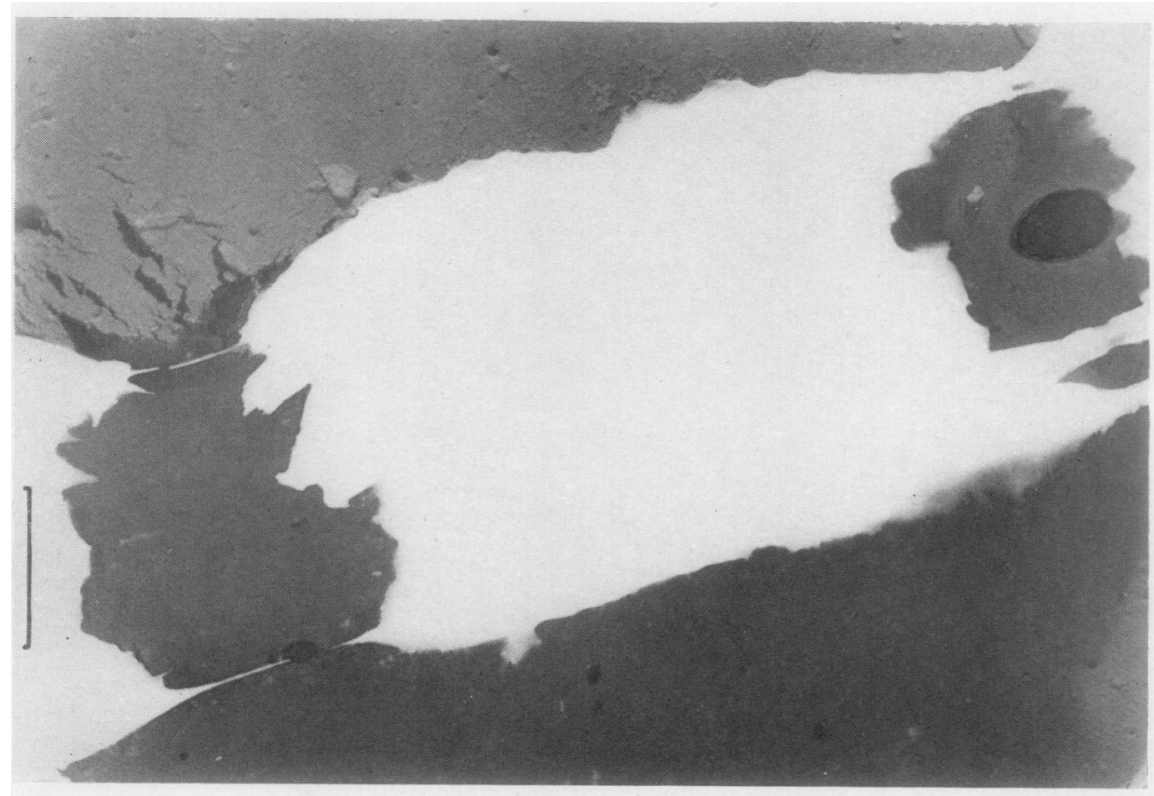

Fig. 30.-Same as Fig. 29. 
31 ), or were in various stages of breakdown, were clear-cut or transforming into "elastin" including isolated rectangular segments which (Fig. 32).

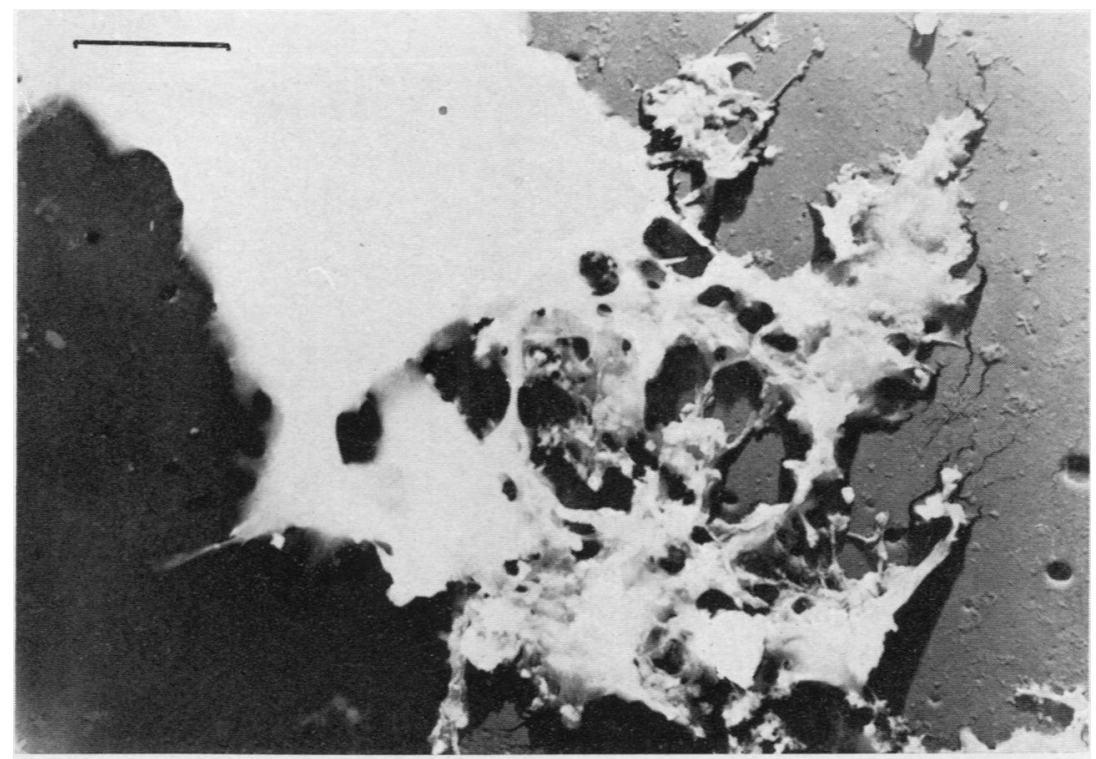

Fig. 31.-Same as Fig. 29, showing an MEF terminating as "elastin” (MEFC).
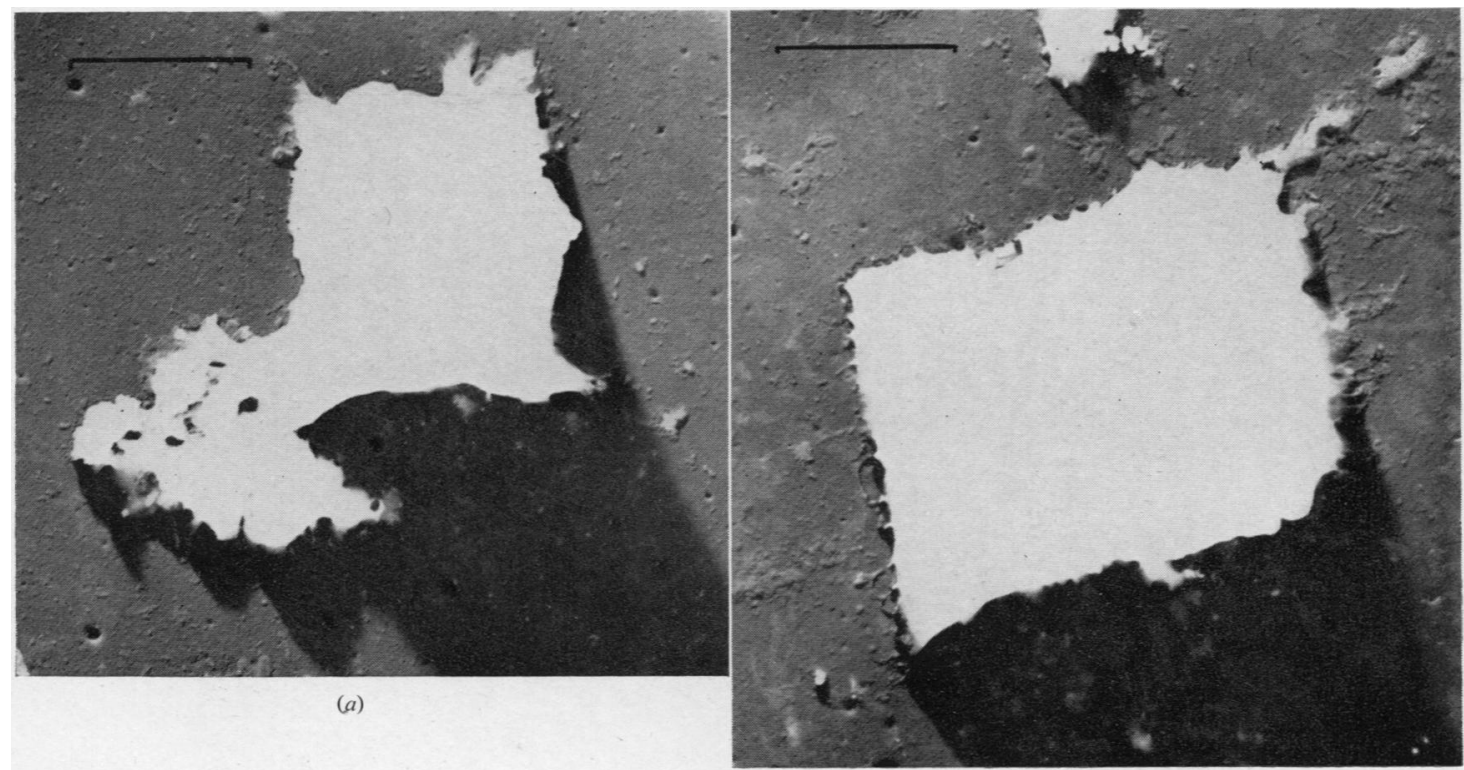

(b)

Fig. 32(a) and (b).-Same as Fig. 29, showing one unaltered, isolated, rectangular segment and one breaking down into "elastin". 
Collagen was absent, fine threads were very scanty, and a few examples of reticulin-like material (as defined by electron microscopists) were seen. (Seebelow.)

The picture was more advanced at $48 \mathrm{hrs,} \mathrm{the}$ MEF being more disintegrated. In addition, scanty, fine fibrous structures resembling reticulin were randomly scattered throughout. Occurring in short lengths or in small patches, their appearance suggested that they could have been formed by the lateral alignment of two or more beaded fibrils (Figs 33 and 34). They were easily distinguishable from the scanty, fine threads also present in the deposit.

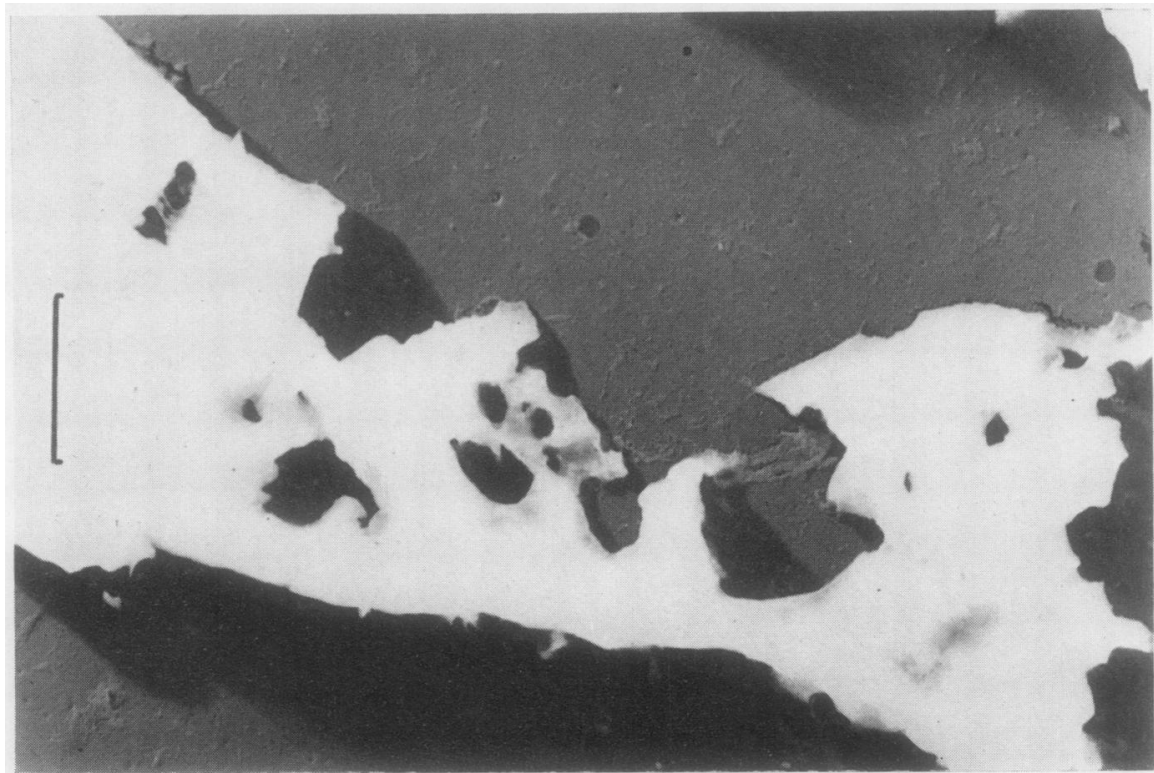

Fig. 33.-Same as Fig. 29 after incubation for $48 \mathrm{hrs}$ at $37^{\circ} \mathrm{C}$. Disintegrating MEF with structures resembling reticulin. The appearance of those situated within the MEF suggests that they may be formed by the lateral alignment of two or more "beaded fibrils".

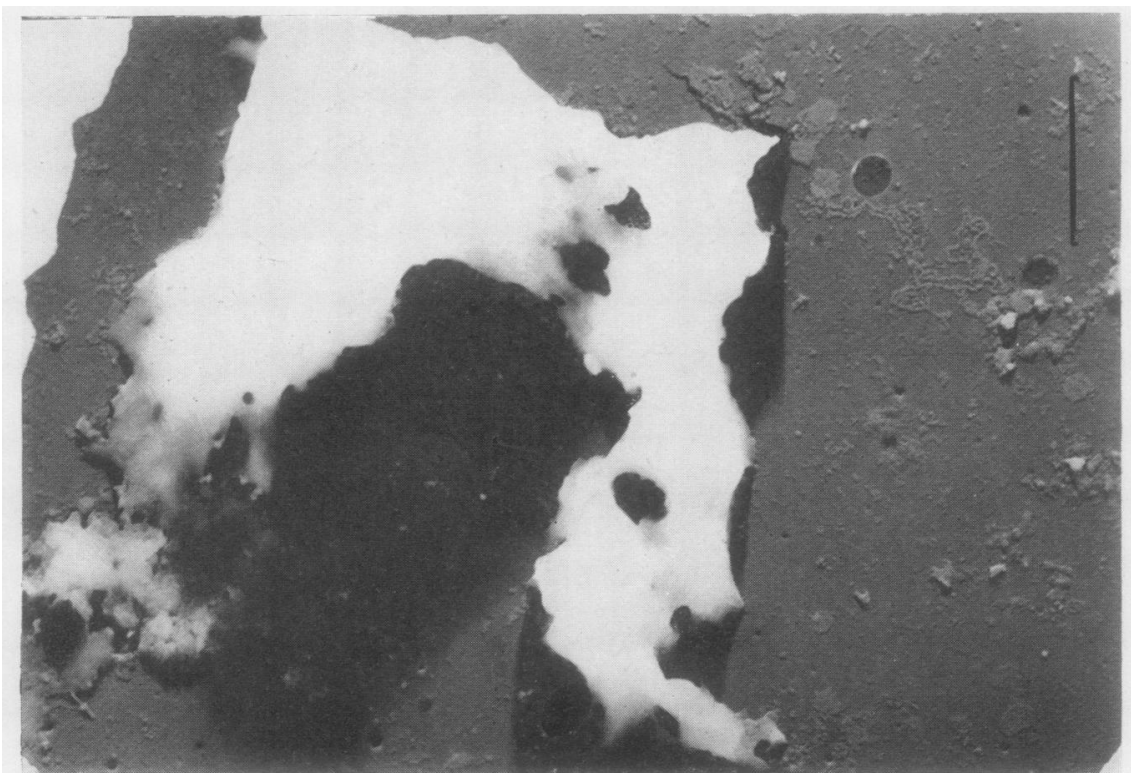

Fig. 34.-Same as Fig. 33. The ? reticulin is present as small patches or as long, winding "beaded fibrils". 
This appearance was much more marked and better visualized after the 48-hr test-tube had been stored in the refrigerator for 3 wks (Figs 35 and 36). All the fields contained a background network of these structures, varying in size from clouds of "beads" to thicker fibres resembling thin, degenerate collagen. Several seemed to bear very fine striations, but the glue-like appearance of the clouds of beads made it difficult to take sharp photographs. Otherwise, the deposit was similar to that examined at $48 \mathrm{hrs}$.

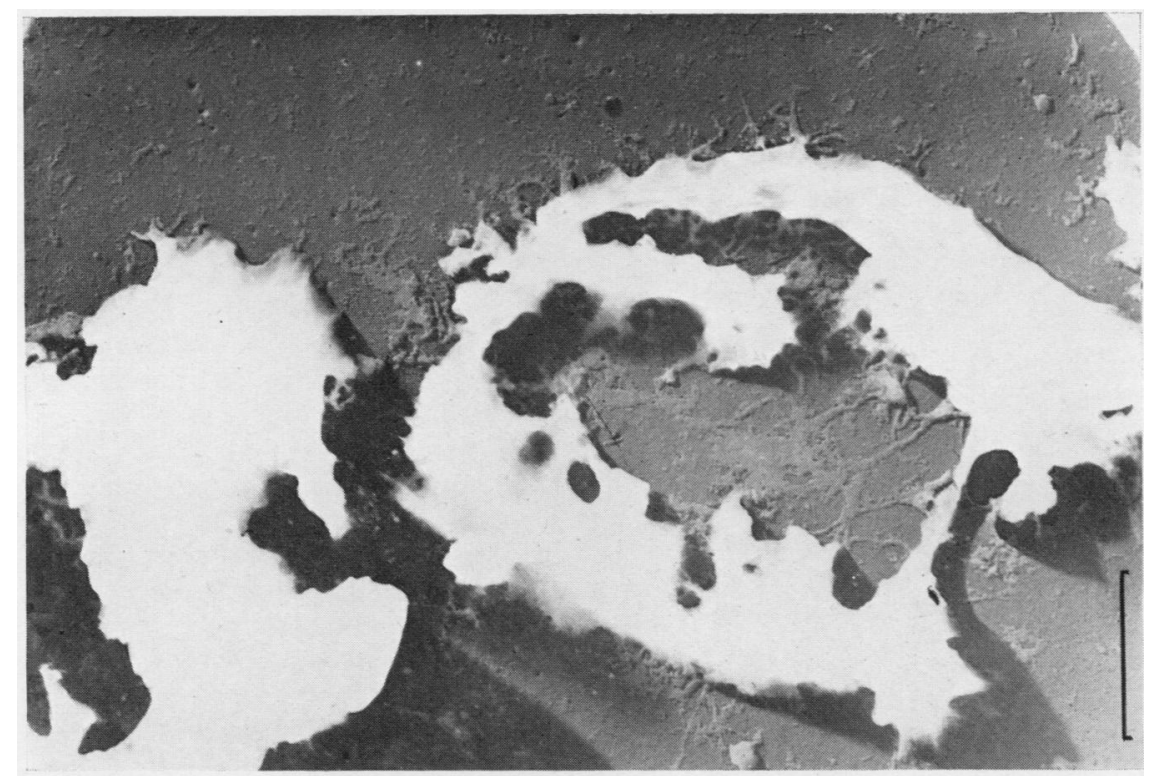

Fig. 35.-Same as Fig. 33 after 3 weeks' storage at $5^{\circ} \mathrm{C}$. Disintegrating MEF and a marked increase in the reticulin-like structures.

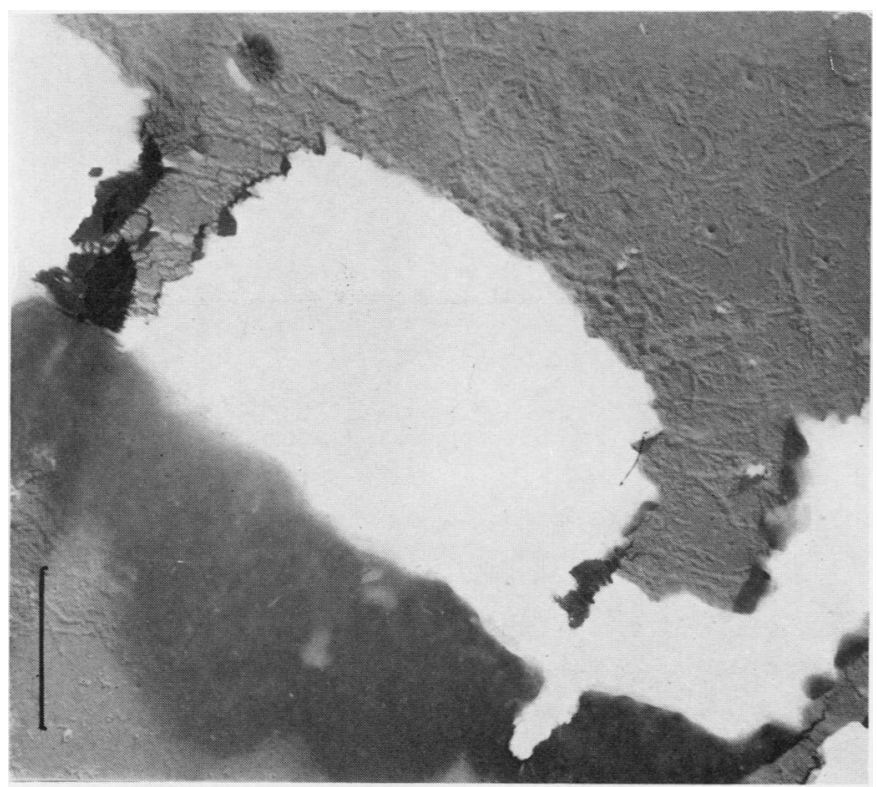

Fig. 36.-Same as Fig. 35 .

The structures are thicker, appear to be finely striated, and resemble young collagen. 


\section{Discussion (Table III)}

The MEF starting material was made up in two batches (Table I). It is difficult to weigh out accurately the tiny amounts of collagenase used, as the preparation consists of particles of varying size. Thus the incubation time required to obtain the "peak effect" of MEF-formation need not necessarily be the same in two similar sets of experiments. The starting material described in the published elastase experiments, using the same 2-year-old collagen (Keech and others, 1956), consisted almost entirely of MEF with no collagen or MEFC. The two batches used in the present study each contained a few MEFC, and some of the MEF were starting to disintegrate, and the second batch contained very scanty collagen (twenty solitary fibrils and a few groups seen in 1,250 fields). This presumably represented an undigested fraction of the original substrate. However, careful analysis does not show that these small variations made any significant difference to the results. It should be pointed out that, although many repeats and control experiments could have been incorporated into this work with advantage, studies were limited by:

(a) the scarcity of the enzyme,

(b) the difficulty in obtaining sufficient skin from a very young child to make enough prepared collagen for a long series of experiments,

(c) the fact that 85-90 per cent. of this prepared substrate is digested in the initial stage, so that the remaining 10 per cent. constitutes the MEF starting material.
The extension of the work using elastase showed that this was the most potent of all the agents employed, producing rapid breakdown of the MEF to the so-called elastic networks which were, in turn, rapidly digested, so that, by $12 \mathrm{hrs,} \mathrm{only} \mathrm{a} \mathrm{few} \mathrm{tiny}$ remnants remained (Table $I$ ). The action of collagenase (at $37^{\circ}$ C.) was much slower, typical MEF still being seen after 12-hrs' incubation. Also, the abundant elastin-like material (networks, filamenting, and MEFC) that was such a feature of the elastase-treated preparation was not nearly so marked. Again, unlike the $p \mathrm{H} 8.8$ series, beaded fibrils, "beads", and fine threads (moderately long and short) were extremely numerous. This suggests that the two enzymes may produce MEF breakdown by different mechanisms. Hyaluronidase, on the other hand (acting in sterile distilled water, $p \mathrm{H} 5 \cdot 6$ ), was intermediate in its rapidity of breakdown between elastase and collagenase. No unaltered MEF were seen after $3 \mathrm{hrs}$ ' incubation, and there was plenty of "elastin" throughout, both as MEFC, "elastic networks", and ribbons of filamenting and "solid" elastin. Unlike preparations treated with collagenase, fine threads were few. The scanty collagen present throughout probably represented the small quantity known to be present in this particular batch of starting material.

Both the borate buffer $(p \mathrm{H} 8 \cdot 8)$ control series and the short-term treatment with ultrasonic radiation gave a valuable pictorial sequence of the slow breakdown of MEF, so that each stage could be studied adequately. The first change appeared to be a reduction in the dense amorphous coating (elasto-

TABLE III

DIAGRAMMATIC SUMMARY OF FINDINGS REPORTED IN THIS PAPER

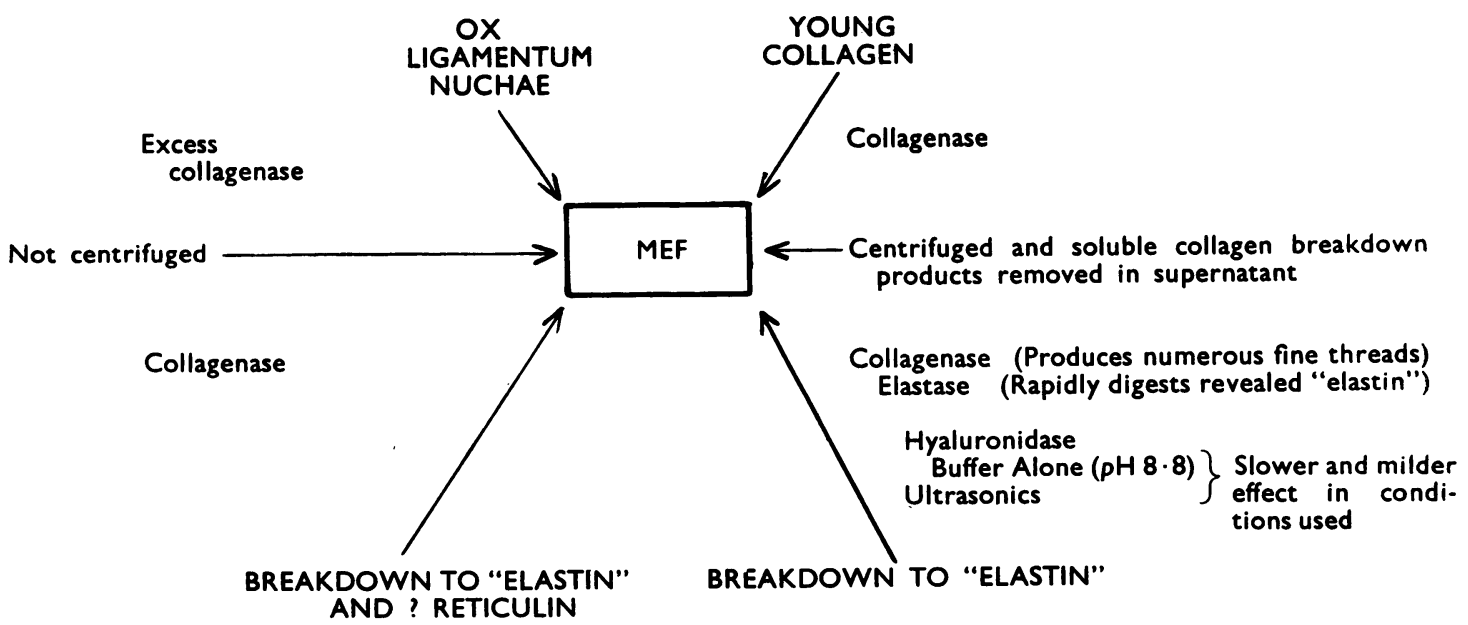


mucin) of the MEF, rendering it narrower and thinner. It was then broken up into short lengths composed of one or several dense rectangular segments, which were either unaltered and clear-cut, or breaking down into "elastin" or amorphous material. These short dense fibres terminating as "elastin" (MEFC) ended either in "elastic networks" or as streamers of filamenting "elastin". The "core" of the MEF appeared to be formed by long ribbons of typical filamenting elastin or by a more solid (thicker) variety of "elastin". This exhibited the same filamentous "longitudinal grain", but contained more elastomucin than typical filamenting elastin. These MEF "skeletons" were best seen on the microscope screen, as they frequently stretched across several fields so that only the smaller examples could be adequately photographed. In the process of scanning the thousands of fields necessary for this study, this picture was repeatedly seen at different stages after all the various treatments used, and proved very convincing. The final remnants of MEF were always the same: irregular patches of amphorous material, large and small angular dense bits, and tiny "elastic networks", with an occasional short dense fibre or small piece of "filamenting elastin".

The problem of what exactly constitutes the "core" of the MEF is rather complicated. Striated, fibrous "links" were illustrated (Keech, 1955) joining the rectangular segments of a proportion of MEF examined, and MEF were believed to be bundles of degenerate collagen with a very thick coating of specialized amorphous material. This view received indirect support from experiments on elastin reported briefly by the British Society for Research on Ageing (1956), Burton, Hall, Keech, Reed, Saxl, Tunbridge and Wood (1955), and by Hall, Keech, Reed, Saxl, Tunbridge, and Wood (1955). Collagenfree ox ligamentum nuchae (as assessed by electron microscopic examination) was suspended in phosphate buffer $(p \mathrm{H} \quad 7 \cdot 3)$ containing collagenase (derived from either $\mathrm{Cl}$. histolyticum or $\mathrm{Cl}$. welchii) and incubated at $37^{\circ} \mathrm{C}$., samples being taken at $1,2,3,4,6,8$, and 24 hrs. Both enzymes produced a progressive fragmentation of the substrate to smaller particles, although, even after $24 \mathrm{hrs,}$ a fair proportion of the substrate remained unaltered. Scanty fully-formed elastin was present throughout. Treatment with both enzymes also revealed striated fibrils (Figs 37 and 38, overleaf) indistinguishable from collagen, often partially coated with amorphous material. These were present in about 25 per cent. of the grid areas examined at 3 and $4 \mathrm{hrs}$, but in later samples had all disappeared. This finding was confirmed on several occasions using different samples on different days. (In the 24-hr specimens treated with the $\mathrm{Cl}$. histolyticum collagenase, some structures closely resembling MEF were seen. The extension of this earlier finding is reported in the present study.) It should be emphasized first, that collagen was only seen within a very limited time range and then rapidly disappeared-presumably digested by the enzyme; secondly, that during this time range only about one quarter of the fields examined contained collagen and lastly that, whether collagen were present or not, a proportion of the elastin substrate became progressively broken down into smaller, less dense pieces, although, even after $24 \mathrm{hrs,} \mathrm{a} \mathrm{fair} \mathrm{amount} \mathrm{still}$ remained unaltered. It would appear, therefore, that only part of the substrate contained the degenerate collagen fibrils. Again, if MEF are heated in water above body temperature, elastin-like structures result (Keech and others, 1956). Thus there is strong morphological evidence suggesting that elastin, or material resembling it, can originate from the breakdown of collagen.

On the other hand, the work reported in the present study strongly suggests that the "core" of the MEF consists of elastin, either "solid" or filamenting in type. This could be explained by the present batches of starting material being "too advanced", i.e. the central degenerate collagen had already become transformed into "elastin". The fact that some of the MEF were already breaking down to form MEFC would support this view.

The experiments on ox ligamentum nuchae were clear-cut, both macroscopically and under the electron microscope (Table II). The collagenasetreated supernatant became opaque, the deposit under the light microscope was much finer than the control and at 35 and 48 hrs (i.e. after the addition of further enzyme) contained large, long, irregular structures in place of the smooth-edged, highly refractile fibres present in both the starting material and the control. It is reasonable to assume that these represented the MEF, which, on electronmicroscopic examination, were found to be very large, stretching across several fields and frequently breaking the collodion. Continued incubation at $37^{\circ} \mathrm{C}$. with collagenase produced MEF-breakdown strictly comparable with the effect of collagenase on preparations of MEF at $37^{\circ} \mathrm{C}$. In addition a small quantity of tiny fibrous structures resembling reticulin, were seen in the $35-$ and $48-\mathrm{hr}$ specimens and these had vastly increased after storage in the refrigerator for 3 wks. In this connexion it should be pointed out that in the experiments on young collagen, the solubilized collagen breakdown products were removed in the supernatant after centrifugation of the collagenase digest, whereas the 


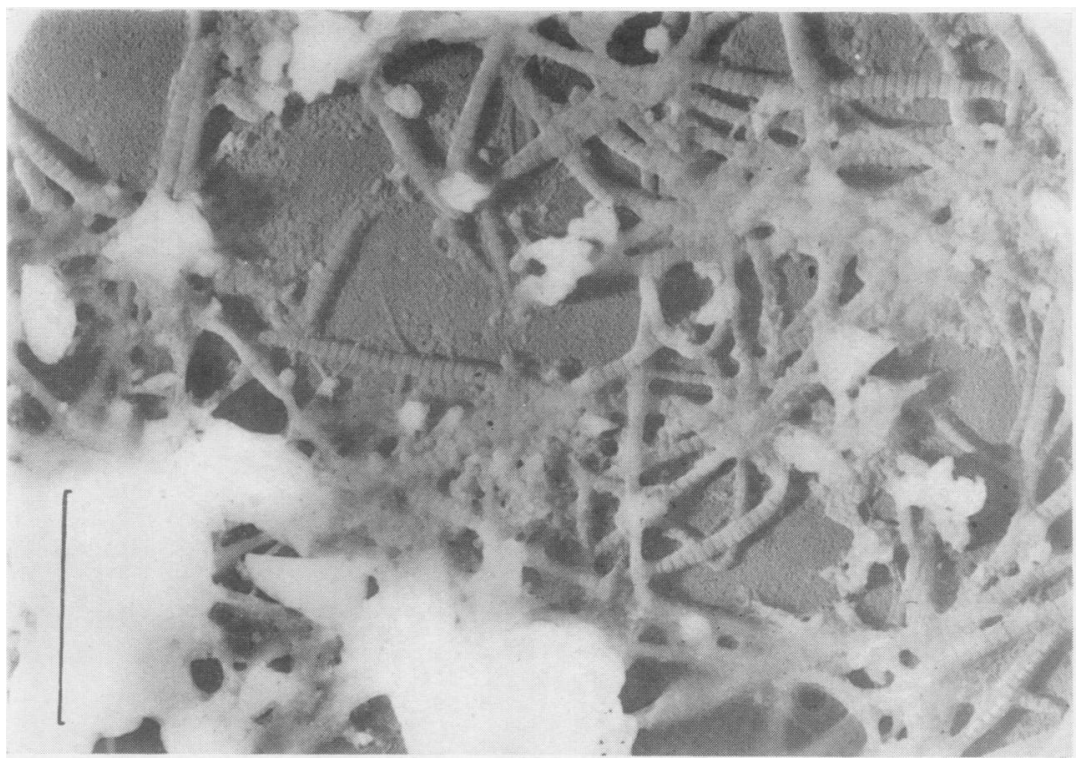

Fig. 37.-Ox ligamentum nuchae elastin after incubation for $4 \mathrm{hrs}$ at $37^{\circ} \mathrm{C}$. with collagenase $(\mathrm{Cl}$. welchii). About 25 per cent. of the fields examined contained striated fibrils indistinguishable from collagen, frequently partially coated with amorphous material.

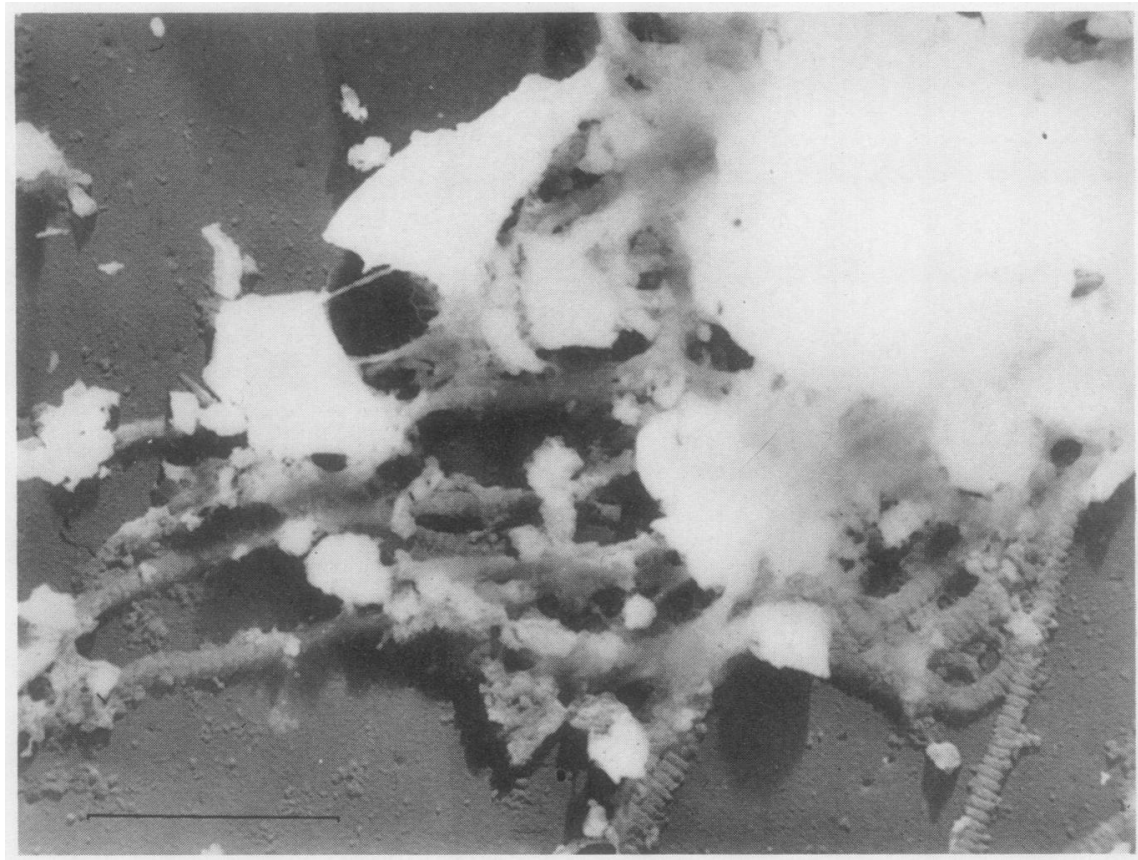

Fig. 38.-Same as Fig. 37, but incubated for $3 \mathrm{hrs}$ at $37^{\circ} \mathrm{C}$. with collagenase derived from Cl. histolyticum. 
elastin preparations were not centrifuged. Thus the possible explanations for the presence of these reticulin-like structures are:

(a) the re-formation of the early collagen (reticulin) from the solubilized breakdown products under the influence of collagenase;

(b) the possibility that collagenase acts in the reverse direction at low temperatures (involvement of the enzyme is suggested by the absence of these structures in the buffer control series);

(c) that they are some bacterial product.

The last is improbable, as the reticulin-like material was seen in both the 35 - and $48-\mathrm{hr}$ specimens which were definitely not contaminated, and only one organism was seen in the refrigerated sample.

A word should be said about the elastin substrate. It was prepared by treating ox ligamentum nuchae with boiling 1 per cent. acetic acid solution for 1 hour. Although this method is frequently used for rendering elastin free from collagen, and although electron microscopic examination shows it to be apparently devoid of collagen fibrils, from the electron microscopic standpoint it is most likely a mixture of:

(1) Solubilized and re-precipitated collagen;

(2) Elastin fibres;

(3) Elastomucin.

It is conceivable that the elastomucin (seen as dense amorphous material and angular dense bits under the electron microscope) could enclose portions of some of the degenerating collagen fibrils during that hour's treatment with acetic acid. These could then be revealed by enzymatic breakdown, and the subsequent formation of MEF (in the presence of excess enzyme) demonstrated in the present study could proceed by utilizing degenerate collagen as their starting point. (This would be in line with the original view that MEF were a specific breakdown product peculiar to the action of collagenase on young collagen.)

It should also be stated that isolated experiments using other agents on the same elastin substrate (elastase, pectinase, periodate) produced breakdown of the substrate without revealing the presence of any collagen fibrils. However, as already pointed out, they appeared within such a limited time range that they could easily be missed unless a special set of timing studies were performed with this object in view.

Thus it would appear that, from the electron microscopic standpoint, objections can be raised against the use of this particular form of elastin substrate, in spite of the fact that, on hydrolysis, elastin preparations obtained in this way give an amino-acid analysis approaching that which is now ascribed to pure elastin.

\section{Summary}

The effect of collagenase, elastase, hyaluronidase, alkaline buffer, and ultrasonic radiation on "motheaten" fibres (collagenase-treated human skin collagen from a 2-year-old child) is described. All the agents produced breakdown of the "moth-eaten" fibres (MEF) to "elastin". This extends previous work (Keech and others, 1956) and confirms that MEF are intermediate structures midway between collagen and elastin.

The action of collagenase on ox ligamentum nuchae elastin is also described, and the disadvantages of using the standard elastin substrates for electron microscopic work are discussed.

It is concluded, from both this and previous studies, that collagen and elastin are not two separate and distinct entities but are probably intimately associated in vivo.

It is a pleasure to thank Professor R. E. Tunbridge, O.B.E., for his sustained encouragement throughout this work, and Dr. J. Sikorski (Textile Department) for use of the ultrasonic equipment.

\section{REFERENCES}

British Society for Research on Ageing (1956). Nature Lond., 177,

467 . bridge, R. E., and Wood, M. J. (1955). Ibid., 176, 966.

Hall, D. A., and Gardiner, J. E. (1955). Biochem. J., 59, 465. Keech, M. K., Reed, R., Saxl, H., Tunbridge, R. E., and Wood, M. J. (1955). J. Gerontol., 10, 388.

Keech, M. K. (1954). Yale J. Biol. Med., 26, 29j.

(1955). Annals of the Rheumatic Diseases, 14, 19.

, Reed, R., and Wood, M. J. (1956). J. Path. Bact., 71, 477.

Ziffren, S. E., and Hosie, R. T. (1955). Proc. Soc. exp. Biol. (N.Y.). 90,650 .

Elucidation enzymatique de la relation entre le collagène et l'élastine: étude au microscope électronique

\section{RÉSUMÉ}

On décrit les effets de la collagénase, de l'élastine, de l'hyaluronidase, du tampon alkalin et de l'irradiation ultrasonique sur les fibres "mangées de mites" (collagène de la peau d'un enfant de 2 ans traité à la collagénase). Tous ces agents produisirent la transformation des fibes "mangées de mites" en élastine. Ceci amplifie les travaux précédents (Keech et coll., 1956) et confirme que les fibres "mangées de mites" sont des structures intermédiaires entre le collagène et l'élastine.

On décrit aussi l'action de la collagénase sur l'élastine du ligamentumnuchae de boeuf, ainsi que les inconvénients de l'emploi des substrata de l'élastine standard pour les études au microscope électronique.

On conclue, à la fois d'après ces travaux et des travaux précédents, que le collagène et l'élastine ne sont pas deux entités distinctes, mais sont probablement intimement associés in vivo.

\section{Elucidación enzimática de la relación entre el colageno y la elastina: estudio al microscopio electrónico. \\ SUMARIO}

Se describen los efectos de la colagenasa, de la elastina, de la hialuronidasa, del tapón alcalino y de la irradiación 
ultrasónica sobre las fibras "apolilladas" (colageno de la piel de un niño de 2 años tratado con colagenasa). Todas estas agencias produjeron la transformación de las fibras "apolilladas" en elastina. Esto amplia los trabajos precedentes (Keech y col., 1956) y confirma el hecho de que las fibras "apolilladas" son estructuras intermedias entre el colageno y la elastina.
Se describe también la acción de la colagenasa sobre la elastina del ligamentum nuchae del buey, así como la desventaja del empleo de substrata de la elastina standard para los estudios al microscopio electrónico.

Se concluye, basándose en trabajos estos y precedentes que el colageno y la elastina no son entidades distintas sino, probablemente, estân intimamente asociados in vivo. 